\title{
Simulation of the mixed-layer circulation in the Arctic Ocean
}

\author{
David M. Holland' and Lawrence A. Mysak \\ McGill University, Montreal, Quebec, Canada \\ Josef M. Oberhuber \\ German Climate Computer Center, Hamburg, Germany
}

Department of Atmospheric and Oceanic Sciences and Centre for Climate and Global Change Research

\begin{abstract}
A numerical simulation of the mixed-layer circulation of the Arctic Ocean is presented using Oberhuber's [1993a] coupled sea ice-mixed layer-isopycnal ocean general circulation model. The model domain includes the Arctic Ocean and the GreenlandIceland-Norwegian (GIN) Sea. The horizontal resolution is $2^{\circ}$. The vertical is resolved using five isopycnal layers, of which the uppermost layer is a turbulent mixed layer. The sea ice is modeled using a thermodynamic-dynamic model which includes a viscous-plastic rheology. Monthly climatological atmospheric forcing is used to spin up the model into a cyclostationary equilibrium. Model results are presented and discussed with respect to observational and previous modeling studies. The mixed layer shows a circulation pattern similar to that inferred from indirect observations and other modeling studies. In an attempt to determine the main driving mechanism for the mixed-layer circulation as produced by the Oberhuber model, a set of sensitivity experiments is carried out. In particular, the relative importance of (1) ice cover, (2) atmospheric winds, (3) surface freshwater fluxes, and (4) initialization with Levitus [1982] data is examined to determine the contribution each makes to the modeled circulation. The key conclusion is that buoyancy forcing is critical to maintaining the mixed-layer circulation.
\end{abstract}

\section{Introduction}

This paper investigates the mixed-layer circulation of the Arctic Ocean using a coupled sea ice-mixed layer-isopycnal ocean general circulation model [Oberhuber, 1993a]. In the Arctic the interaction of the atmosphere with the mixed layer is different than in other ocean basins because of the presence of sea ice. First, the sea ice may either enhance or diminish the wind-driven component, depending on the absence or presence of ice internal stress. If the latter is small, then the wind forcing in an ice-covered ocean is larger than in an ice-free ocean because the ice surface has a larger drag coefficient and the ice transmits nearly all the enhanced surface wind stress to the ocean surface. However, if the ice internal stress is large, little wind momentum is transferred to the ocean surface; most of it is absorbed by the ice. In the extreme case of landfast ice, no wind momentum is transferred to the ice at all. The ice and ocean velocities are zero, as is the ice-water drag. Second, ice melt (growth) provides a positive (negative) freshwater flux to the ocean surface in addition to that of river runoff and that of precipitation (or evaporation). This ice-related freshwater flux modifies the buoyancy-driven circulation and is particularly important in an ocean where density is controlled only by salt. Consequently, the Arctic has a mixed-layer circulation in which the relative importance of the wind-driven and buoyancydriven components is distinctly different than in other basins. The purpose of this paper is to simulate the mixed-layer cir-

\footnotetext{
${ }^{1}$ Now at Lamont-Doherty Earth Observatory, Columbia University, Palisades, New York.

Copyright 1996 by the American Geophysical Union.

Paper number 95JC02819.

0148-0227/96/95JC-02819\$05.00
}

culation and to identify the relative importance of each component in determining the total circulation.

Although this study uses a fully coupled sea ice-mixed layerisopycnal ocean model, the results presented emphasize only the mixed-layer response under various sensitivity studies. Throughout this paper the "circulation" refers to that of the mixed layer. The sea ice model above the mixed layer and the deep-ocean model below are considered as providing forcing for the mixed layer. From the point of view of the mixed layer the sea ice supplies momentum due to ice motion, a positive (negative) freshwater flux due to ice melt (growth), and a reduced heat exchange due to the insulating effect of sea ice. Also, it is important to note the following feedback: not only does the sea ice cover affect the mixed layer, but the mixed layer is equally effective in altering the sea ice cover. Concerning the deep ocean (i.e., that part of the ocean beneath the mixed layer), the mixed layer exchanges momentum, mass, heat, and salt with the deep ocean via interfacial stresses, entrainment, and diffusion. Again, feedback processes are present as the deep ocean can produce changes in the mixed layer and vice versa.

An unfortunate aspect of current ocean modeling practice is to include a nonphysical relaxation term of the modeled surface salinity to that of the observed surface salinity. This negative feedback term is required in order to prevent the climatology of an ocean model from drifting far away from the present-day observed one. It represents a catchall correction term for the models cumulative errors in advection, convection, and physical surface fluxes. Future improvements in ocean modeling will see the role of this term diminished, if not eliminated.

A brief review of observational studies of the mixed-layer water mass properties and circulation is now presented. This is 
followed by a brief review of previous modeling studies. A complete review of observational and modeling studies is given by Smith [1990].

\subsection{Observed Features}

The observed features of the mixed layer that are of relevance to this study include the temporal and spatial variations of the temperature and salinity distribution, the mixed-layer depth, and, most important of all, the circulation. The longterm means of the above quantities are not well known. The remoteness of the Arctic has thus far prohibited the collecting of sufficient data to determine a satisfactory climatology.

Ice-covered regions have a mixed-layer temperature equal to that of the freezing point of seawater at the ambient salinity. The ocean waters directly beneath the permanent ice cover thus show little variation in temperature. The marginal ice zone does not show significant variations in temperature; however, it is the northward transport of warm North Atlantic waters into the Norwegian Sea and on into the Barents Sea that provides the warmest mixed-layer water temperatures and the greatest seasonal variations [see Parkinson et al., 1987, Figure 2.5].

Large spatial variations in salinity are caused by river runoff, ice growth/melt, and, to a lesser extent, evaporation/ precipitation. The spatial pattern shows large-scale freshwater tongues extending from the mouths of the major rivers along both the Siberian and North American coastlines. Conversely, the inflow of saline water from the Greenland-IcelandNorwegian (GIN) Sea produces a saline tongue into the Arctic just north of Spitsbergen as well as into the Barents Sea. There is a weaker saline tongue of Pacific water that enters the Arctic via the Bering Strait. The seasonal variation in spatial pattern of surface salinity [see Parkinson et al., 1987, Figure 2.4] is the greatest during the summer when river runoff is at a maximum.

The mixed-layer depth in the Arctic is between 25 and $50 \mathrm{~m}$ [Björk, 1989]. The presence of a strong halocline (pycnocline) prevents the mixing of the mixed-layer waters with the deeper waters. (We recall that near freezing temperatures, the use of the term halocline or pycnocline is interchangeable.) In contrast to the relatively shallow mixed-layer depths in the Arctic, the GIN Sea has large mixed-layer depths, of order $1000 \mathrm{~m}$, due to convective overturning in that region during winter.

The mixed-layer circulation is generally believed to consist of the anticyclonic Beaufort Gyre (BG) in the Canadian Basin and the Transpolar Drift Stream (TDS) in the Eurasian Basin, extending from Siberia toward Fram Strait (see Figure 1a). Average speeds in the BG are of the order of $2-3 \mathrm{~cm} / \mathrm{s}$. This view of the mixed-layer circulation is based upon the work of Coachman and Barnes [1961], who deduced the circulation from some 300 oceanographic stations and constructed a dynamic height field. They assumed a level of no motion at a depth of $1200 \mathrm{~m}$. It is not evident why there should be a level of no motion at such a depth. Furthermore, in terms of actual current measurements, they mention that in many instances the actual currents were not measured, but rather, that they were inferred from the motion of the sea ice under the assumption that the sea ice and ocean circulation follow one another. This may not be a good assumption. An apparently stronger argument, in support of the ocean circulation following the sea ice flow, is that the observed motion of large ice islands with deep drafts $(40 \mathrm{~m})$ followed an anticyclonic BG trajectory and a TDS. The assumption is that the motion of these deep-draft ice islands is controlled by the ocean circula- tion. This assumption ignores the important fact that the ice islands are not floating in isolation but are immersed in a field of sea ice which is capable of transmitting stresses on the ice islands that may exceed the stress transmitted by the ocean currents. This means that large-scale wind patterns can cause the sea ice to produce an internal stress field that may force the motion of an ice island that is different from that due to ocean currents. This point has been discussed by Hibler and Bryan [1987, Figure 12b].

An update to the circulation pattern of Coachman and Barnes [1961] was made by Newton [1973]. He concluded that the general circulation of the Arctic (surface) water in the Canada Basin is the same as that inferred by Coachman and Barnes [1961]. He reiterated that the circulation has been confirmed by the drift tracks of both deep ( $40-50 \mathrm{~m}$ ) ice islands and shallow (2-3 m) ice floes. He used data from the Arctic Ice Dynamics Joint Experiment (AIDJEX) from 1970 to 1972 in which current meters were placed down through holes cut in the ice. The current meters were secured to the ice which moves with respect to the water; thus the recorded currents were relative to the ice and were corrected for ice drift to present a true picture of the currents with respect to Earth. Furthermore, no error bounds were formally established on the AIDJEX current meter data. Newton notes that the current meters were often operating below their accuracy threshold of about $2.5 \mathrm{~cm} / \mathrm{s}$. In fact, many of the currents reported were of this magnitude. Interestingly enough, during the 1972 AIDJEX experiment the measured surface currents at one of the three camps were opposite to the general circulation picture of Figure 1a. This anomalous current was located along the Siberian shelf.

An intriguing report of circulation in the southern Beaufort Sea was made by Aagaard [1984], who took current meter measurements and station data over the continental slope in that area. He reported a large-scale circulation (the Beaufort Undercurrent) flowing toward Fram Strait (see Figure 1b) and not toward Bering Strait, as in Figure 1a. He suggested that this flow is part of the large-scale general circulation over the basin. As these measurements probably represent the best measurements of flow in that region, it is possible that the currents in the extreme southern half of the BG are moving opposite to the ice circulation.

A large-scale view near the surface of the Arctic Ocean is to consider it as a system of three overlying geophysical fluids. The top layer of air is the atmospheric planetary boundary layer of thickness of order $1 \mathrm{~km}$. The surface winds that are associated with the mean atmospheric pressure field would show a pattern similar to that of the ocean circulation (Figure 1a). The second layer of sea ice is of thickness of order $3 \mathrm{~m}$. The mean pattern of ice drift (Figure 2) shows a pattern that is consistent with the atmospheric circulation. The bottom layer is the ocean mixed layer of thickness of order $40 \mathrm{~m}$. Observational evidence collected over the last 10 years clearly shows that the mean atmospheric circulation pattern and the mean sea ice circulation pattern are well known and similar to

Figure 1a. (opposite) Composite surface circulation inferred from dynamic topography station drifts, and temperature and salinity distributions [after Coachman and Aagaard, 1974]. (Copyright 1974 by Springer-Verlag, New York, Incorporated. Reprinted with permission.) Dynamic topography is based on a level of no motion at 1200 dbar. 


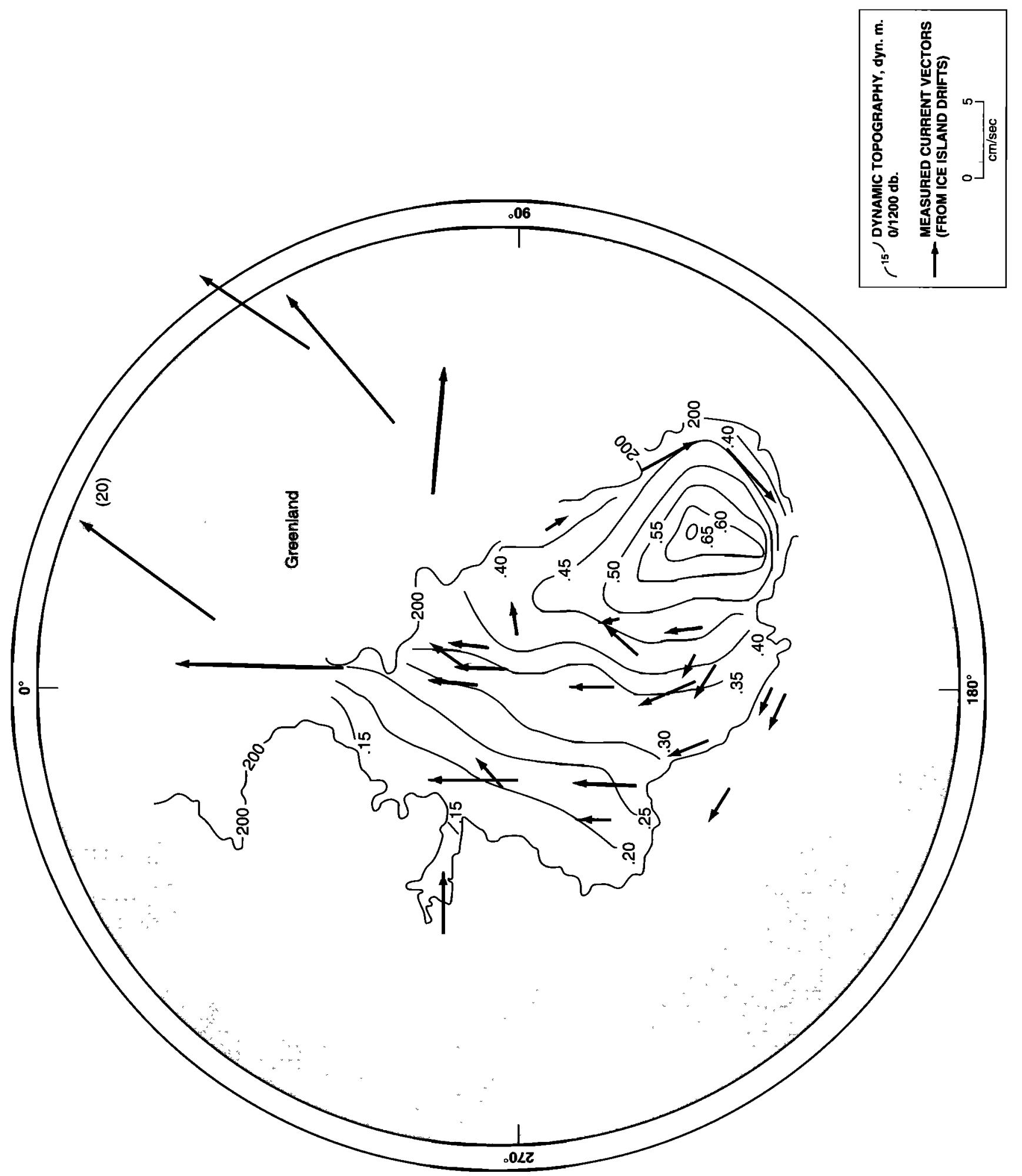




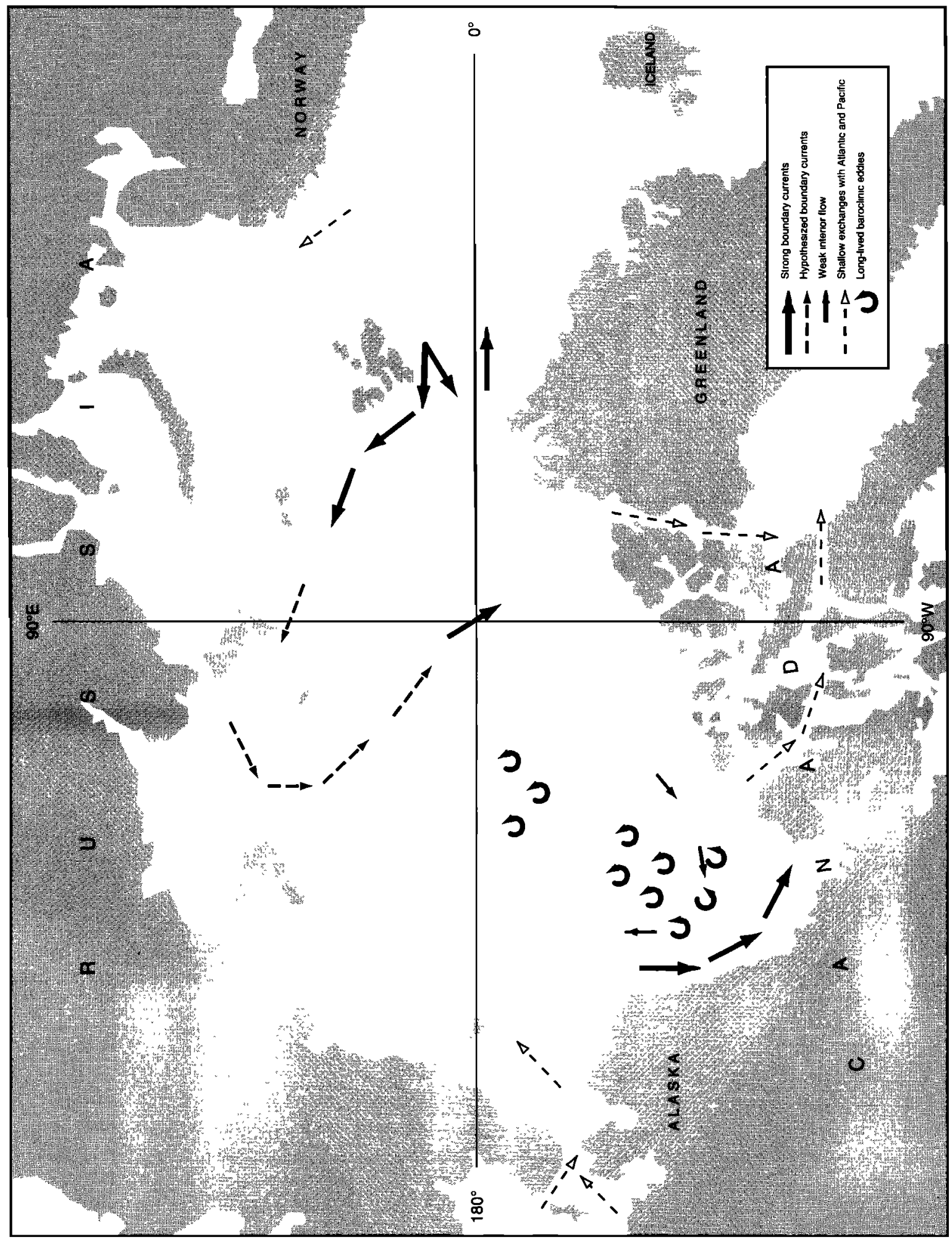

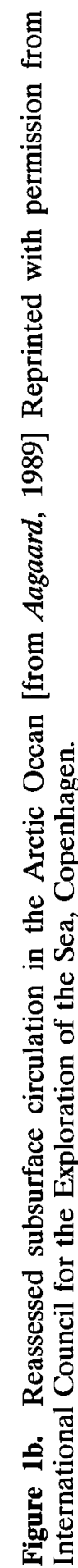




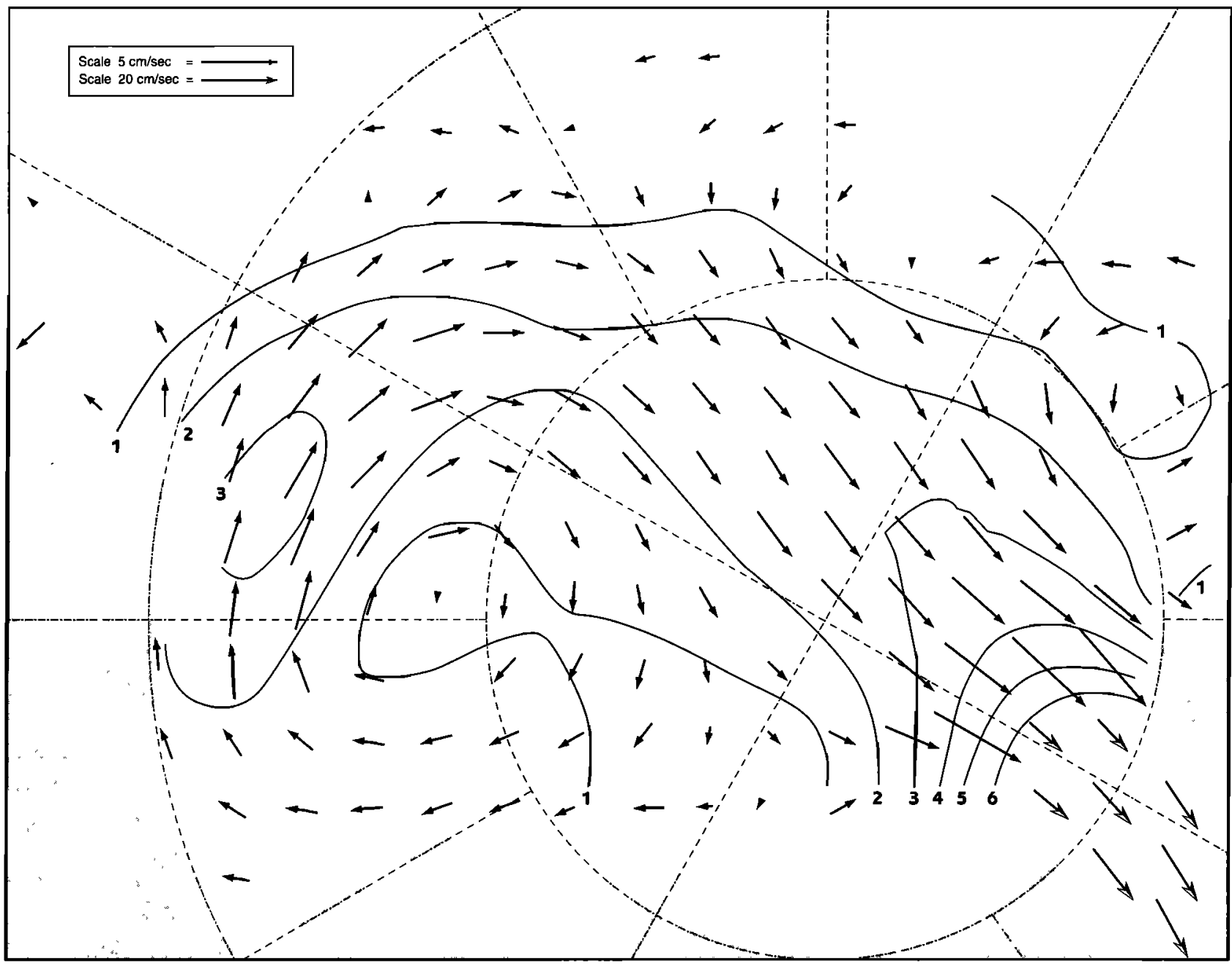

Figure 2. Mean field of ice motion interpolated spatially and temporally from manned ice stations and automated data buoys [from Colony et al., 1991].

one another [Colony et al., 1991]. This suggests that the winds control the sea ice circulation. However, the mixed layer does not directly feel the atmospheric wind stress; the stress provided by the slowly rotating pack ice may be too small to move the entire mixed layer with it and therefore its motion can be significantly driven by buoyancy effects.

\subsection{Previous Modeling Results}

The first computer simulation of the Arctic Basin circulation was carried out by Campbell [1965], who produced a steady state circulation of a wind-driven, baroclinic, ice-covered Arctic Ocean. His solution showed an anticyclonic BG [Campbell, 1965, Figure 7] over the Canadian Basin in agreement with our Figure 1a. Galt [1973] carried out a large-scale modeling study of the Arctic which presented a solution of the barotropic vorticity equation forced by the curl of the wind stress. The resulting flow consisted of an anticyclonic BG and a TDS directed toward Fram Strait [Galt, 1973, Figure 14]. Both of these studies involved wind-driven flows in which the thermohaline circulation and the exchange of water masses with various straits was ignored. Semtner [1976, Figure 7] used a baroclinic ocean model which simulated the anticyclonic flow of the BG and the TDS. However, his study did not include an ice cover. The first three-dimensional (3-D) coupled sea iceocean model was presented by Hibler and Bryan [1987]. Although they emphasized the sea ice simulation, some results were presented for the ocean surface circulation. Their flow showed an anticyclonic BG and a TDS [Hibler and Bryan, 1987, Figure 11]. Semtner [1987] presented a coupled sea ice-ocean model similar to that of Hibler and Bryan (with a simplified sea ice rheology) and obtained the same circulation pattern.

The modeling study of most relevance to the present one is that of Ranelli and Hibler [1991], who, using the same model as that of Hibler and Bryan [1987], investigated the importance of the salt budget to the general circulation in the Arctic Ocean. Their main conclusion was that the salt budget has an impact on the Arctic Ocean circulation by means of modifying the Arctic Basin stratification. Specifically, they showed that the absence of precipitation caused a substantial reduction in the intensity of the Arctic circulation, and conversely, the absence of ice transport, which yields more net freshwater in the Arctic Basin, resulted in an intensification of the circulation.

Nearly all previous general circulation modeling studies have been based on the Bryan-Cox ocean model [Cox, 1984]. Part of the motivation for the present work is the availability of a new type of ocean general circulation model developed by 
Oberhuber [1993a]. This model differs from the Bryan-Cox model in that it uses isopycnal surfaces as the vertical coordinate. The vertical coordinate is thus Lagrangian rather than Eulerian. The flow in the horizontal plane is then naturally directed along isopycnal surfaces. This new model is applied to the Arctic Basin with the goal of investigating the water mass properties and circulation of the mixed layer. This paper complements the study of Holland et al. [1996], where the model is used to simulate the subsurface Atlantic layer circulation in the Arctic and its connection with the North Atlantic circulation. Oberhuber [1993b], on the other hand, used the model to study the circulation only in the North Atlantic Ocean.

The remainder of this paper is organized as follows. Section 2 briefly describes the layout of the coupled sea ice-mixed layer-isopycnal ocean model. The simulated mixed-layer water mass properties and circulation are presented in section 3 . Section 4 presents the water mass properties and surface circulation for four sensitivity experiments in which (1) the sea ice model is removed, (2) the wind forcing is turned off, (3) the surface freshwater flux is modified, and (4) the model is spun up without Levitus [1982] initialization data. Section 5 concludes the paper.

\section{The Model}

The model used for this study is that of Oberhuber [1993a]; it consists of three coupled submodels. The sea ice is represented by a dynamic-thermodynamic model with viscousplastic rheology [Hibler, 1979], the mixed layer by a turbulent kinetic energy model, and the deep ocean by an isopycnal-layer model. The models interact via the exchange of momentum, mass, heat, and salt. Forcing occurs via the specification of monthly climatological atmospheric fields, and realistic topography [National Geophysical Data Center, 1987] is employed (within the limitations of the horizontal grid spacing used). The equations describing each model are fully described by Oberhuber [1993a]. They are briefly presented below, followed by a description of the model layout.

\subsection{Sea Ice}

For the momentum balance the ice is considered to move in a two-dimensional spherical plane with forcing fields operating on the ice via simple planetary boundary layers. The nonlinear inertial terms are neglected, as in previous ice models [e.g., Hibler, 1979]. The momentum equation is given by

$\partial_{\imath} h \mathbf{v}=\boldsymbol{\nabla} \cdot A^{m} \boldsymbol{\nabla} \mathbf{v} h-\mathbf{f} \times \mathbf{v} h-g h \boldsymbol{\nabla} \Gamma+\tau_{u}+\tau_{o}+\mathbf{I}$,

where $\mathrm{v}=(u, v)$ is the horizontal velocity vector, $h$ is the ice thickness, $A^{\prime \prime \prime}$ is the horizontal diffusion coefficient for momentum, $f$ is the Coriolis vector, $g$ is the acceleration due to gravity, $\Gamma$ is the sea surface elevation, $\tau_{u}$ is the ice surface wind stress, $\tau_{o}$ is the ice bottom current stress, and $I$ is the internal ice stress represented as viscous plastic. The ocean currents used in the parameterization of the ice bottom current stress are those of the mixed layer of the ocean model.

The ice-cover thickness $h$ is modeled as a continuous nonnegative variable. The presence of leads in the ice is modeled using a variable called the ice compactness $q$ which is defined as the fraction of a grid cell area covered by ice; the rest of the cell contains open water.

The spatial and temporal variations in thickness and compactness are modeled by the continuity equations

$$
\begin{aligned}
& \partial_{i} h=-\nabla \cdot \mathrm{v} h+\nabla \cdot A^{s} \nabla h+F_{h} \\
& \partial_{l} q=-\nabla \cdot \mathrm{v} q+\nabla \cdot A^{s} \nabla q+F_{q},
\end{aligned}
$$

where $F_{h}$ and $F_{q}$ are thermodynamic forcing or source terms which are described in detail by Holland et al. [1993]. The numerical diffusion terms for these scalar equations have coefficient $A^{s}$.

\subsection{Mixed Layer}

The sea ice and deep-ocean models are coupled through an ocean mixed-layer model. The mixed layer has vertically uniform velocity, temperature, and salinity. The uniformity is produced by both wind-stirring and surface buoyancy fluxes. The mixed-layer depth is controlled by both local mixing and the horizontal convergence of mass, heat, and salt. The mixed layer is, in fact, the uppermost layer of the deep-ocean model and always has a nonzero thickness and an arbitrary instantaneous potential density. This is in contrast to the deeper layers which may have a zero thickness and always have a prescribed potential density. The mixed layer differs from the deeper layers in that it is directly forced by a surface buoyancy flux due to heat and freshwater fluxes. As a result, the mixed layer depth $h$ changes through the process of entrainment. The equation for the entrainment rate $w$ is given by

$$
w g^{\prime} h-w R i_{c}\left(\Delta u^{2}+\Delta v^{2}\right)=a u_{*}^{3}+b B,
$$

where $g^{\prime}$ is the reduced gravity; $R i_{c}$ is the critical Richardson number, $\Delta u^{2}$ and $\Delta v^{2}$ is the difference in the squares of the velocity components between the mixed layer and the layer below it, respectively; $a$ and $b$ are weighting coefficients; $u_{*}$ is the friction velocity; and $B$ is the surface buoyancy flux. The first term on the left-hand side of (4) describes the production of mean potential energy due to the vertical displacement of isopycnals; the second term describes the production of mean kinetic energy due to vertical velocity shear. On the right-hand side the first term stands for the production of turbulent kinetic energy due to wind stirring; the second term is the buoyancy flux which is induced by heat and freshwater fluxes. The parameterization of the buoyancy flux varies according to whether the ocean surface is ice-covered or ice-free. The reader is referred to Oberhuber [1993a] for details of this parameterization.

\subsection{Deep Ocean}

The representation of the oceanic flow along isopycnal layers is motivated by the assumed diabatic nature of the subsurface ocean. The use of isopycnal coordinates allows flow to occur naturally along isopycnal surfaces. There are many difficulties in the physical realization of such a model, such as the intersection of isopycnal surfaces either with the sea surface or with the bathymetry, the parameterization of cross-isopycnal mixing, and the representation of convection. The reader is referred to Oberhuber [1993a] for a discussion of these issues.

The model discretizes the water column into layers of prescribed potential density. Both the depth of a layer beneath the surface and its thickness vary temporally and spatially due to mass flux divergence, entrainment, and cross-isopycnal mixing. A layer is permitted to migrate vertically up or down, increase or decrease its thickness, and intersect with the surface (actually the mixed layer) or bathymetry. This freedom of movement allows the model to optimally represent a highly stratified 


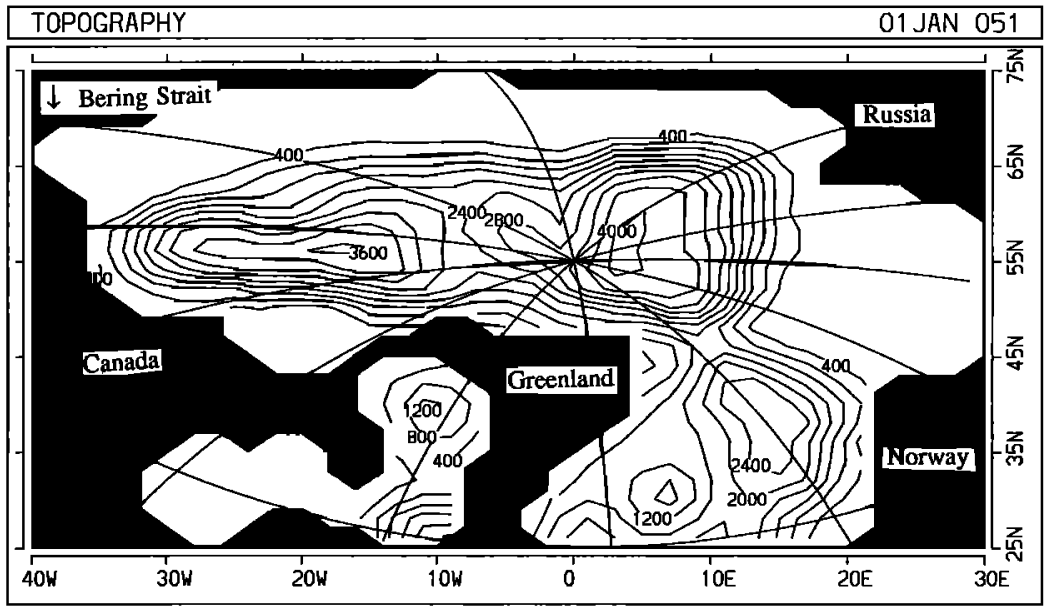

Figure 3a. Bathymetry and model domain. The domain includes the Arctic Ocean and the GreenlandIceland-Norwegian (GIN) Sea. The bathymetry resolves the Canadian Basin and the Eurasian Basin, which are separated by the Lomonosov Ridge which runs from Siberia to Greenland as it passes beneath the north pole. The Fram Strait sill has a depth of about $2500 \mathrm{~m}$. Baffin Bay and Hudson Bay are also included; however, they have no connection with any other part of the domain.

water column by having many thin isopycnal layers near the pycnocline; at the same time it can represent a well-mixed water column by a few, relatively thick layers. The advantage of isopycnal coordinates is that as the water column changes its stratification either spatially or temporally, the coordinate system adjusts to adequately represent it.

Within each layer the mass flux, mass content, heat content, and salt content are prognostically computed. The basic equations (as applied individually to each isopycnal layer) are formulated in flux form as conservation equations for the vertical mean of the mass flux $\rho h \mathbf{v}$, mass content $\rho h$, heat content $\rho h \theta$, and salt content $\rho h S$ as follows:

$$
\begin{aligned}
\partial_{t}(\rho h \mathbf{v})= & -\nabla[\mathbf{v}(\rho h \mathbf{v})]-h \boldsymbol{\nabla} p-\mathbf{f} \times(\rho h \mathbf{v}) \\
& +\nabla \cdot A^{m} \nabla(\rho h \mathbf{v})+\Omega[\rho \mathbf{v}]+\boldsymbol{\tau} \\
& \partial_{t}(\rho h)=-\nabla \cdot(\rho h \mathbf{v})+\Omega[\rho]+R^{p-e} \\
\partial_{l}(\rho h \theta)= & -\nabla \cdot[\mathbf{v}(\rho h \theta)]+\nabla \cdot A^{s} \nabla(\rho h \theta)+\Omega[\rho \theta]+Q
\end{aligned}
$$

$$
\partial_{t}(\rho h S)=-\nabla \cdot[\mathbf{v}(\rho h S)]+\nabla \cdot A^{s} \nabla(\rho h S)+\Omega[\rho S]+R^{l},
$$

where $\mathbf{v}=(u, v)$ is the layer velocity, $h$ is the thickness, $\theta$ is the potential temperature, $S$ is the salinity, $\rho$ is the potential density, $p$ is the in situ pressure, $\mathrm{f}$ is the Coriolis vector, $A^{m}$ is the diffusion coefficient for momentum, $A^{s}$ is the diffusion coefficient for heat and salt, $\Omega[\gamma]$ is the cross-isopycnal transfer of a quantity $\gamma, \tau$ is the stress between a given layer and the layer above it as well as the stress between the given layer and the layer below it, $Q$ is the heat flux into a layer, $R^{p-e}$ is the freshwater flux due to precipitation minus evaporation, and $R^{t}$ is the freshwater flux due to the sea ice-ocean coupling. It should be noted that the stress at the surface of the ocean is a nonlinear drag law based on the ice and wind velocity. The relative contribution of ice drag and wind is weighted by the percentage areal coverage of ice.

\subsection{Model Layout}

The domain chosen for this study includes the Arctic Ocean and the GIN Sea. The model places a solid wall across the Bering Strait, the Canadian Arctic Archipelago, the Denmark Strait, and the passage between Iceland and Europe. Consequently, the model does not allow for the inflow of warm, fresh Pacific water via Bering Strait, nor the outflux of cold, fresh Arctic Surface water via the Canadian Arctic Archipelago, nor the interaction with the warm, saline northern Atlantic.

The model's bathymetry is obtained by interpolating a $1^{\circ}$ resolution topographic data set onto the model's grid of $2^{\circ}$ resolution. The main bathymetric features of the Arctic and GIN basins are preserved (Figure 3a).

A problem with numerical models written in spherical coordinates for the Arctic Ocean is the convergence of meridians of longitude near the north pole. The resulting small east-west grid spacing near the pole leads to unrealistically small time step constraints. This is overcome by rotating the model coordinates through Eulerian angles such that the model coordinates converge to a point in northern Siberia, which is outside the defined model domain. All figures presented in this chapter indicate the rotated latitude and rotated longitude coordinates along their axes. The true geographical coordinates are superimposed on the figures as thin solid lines (e.g., Figure 3a).

The model resolves the water column using five vertical layers of prescribed potential density. The initial prescribed density and thickness of each layer is obtained via interpolation of the temperature and salinity data of Levitus [1982]. The numerical values of the assigned density values are 1024.07, $1025.08,1026.09,1027.10$, and $1028.10 \mathrm{~kg} / \mathrm{m}^{3}$. As the model integrates in time, these layer thicknesses vary in time and space; however, the densities do not. The first layer, which is the mixed layer, is allowed to develop a temporally and spatially varying potential density because of entrainment and surface buoyancy fluxes. The model uses spherical coordinates in the horizontal with a resolution of $2^{\circ}$ in latitude and longitude. As the model coordinates are rotated by Eulerian angles 


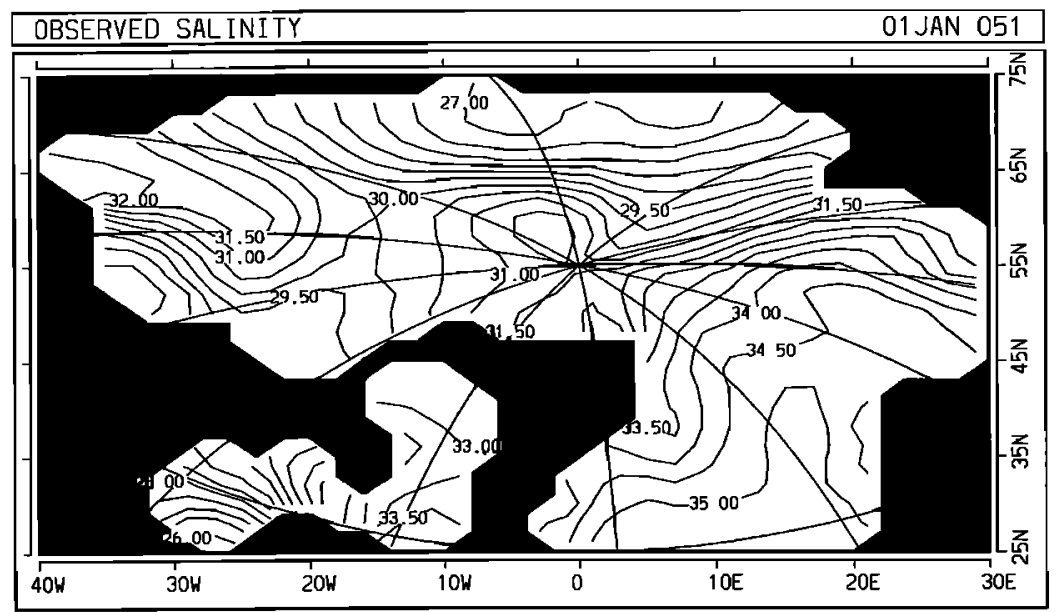

Figure 3b. The observed January sea surface salinity distribution based on data from Levitus [1982]. The model relaxes its surface salinity to this field. Note the low-salinity values along the peripheral of the Arctic corresponding to river freshwater input. Also evident is the salinity of the Bering Strait inflow of 31 psu. The highest salinity is associated with the inflow to the Arctic of the saline ( 35 psu) water from the GIN Sea.

with respect to geographical coordinates, the result is a spatial resolution of about $150 \mathrm{~km}$ in the Arctic.

The model spin-up is for 50 years with a time step of 1 day. This is an adequate time for the sea ice and mixed-layer models to reach an equilibrium; however, the deep-ocean circulation almost certainly is not in absolute equilibrium after such a short period. There still exists a small residual drift in the water mass properties of the deep ocean, but they are not of relevance in the context of the present study. One simulated decade requires one hour of CPU time on a Cray supercomputer.

The surface boundary conditions on salinity and temperature are essentially of Newtonian type. The observed salinity field to which the model salinity is relaxed has a seasonal cycle; the January field is given in Figure $3 \mathrm{~b}$. The relaxation timescale is strong, with an $e$-folding value of 11 days. The surface temperature is not directly relaxed to observed values; instead, sea surface temperature is relaxed to an apparent air temperature.
The apparent temperature is computed as the result of a complete surface energy balance that includes longwave, shortwave, sensible, and latent heat terms (see Oberhuber [1993a] for details).

The model is forced using monthly climatological fields of wind stress, radiation, air temperature, humidity, rainfall, and cloud cover. These fields are described by Oberhuber [1988] and Wright [1988]. The model derives the forcing at a particular time step by interpolating between climatological fields of neighboring months. An example of the wind stress is shown in Figure $3 c$, which serves to illustrate the typical wind stress pattern in the Arctic during winter.

\section{Control Run Simulation}

As stated in section 2, the mixed layer is actually the top layer of the isopycnal ocean model. At each grid point in the

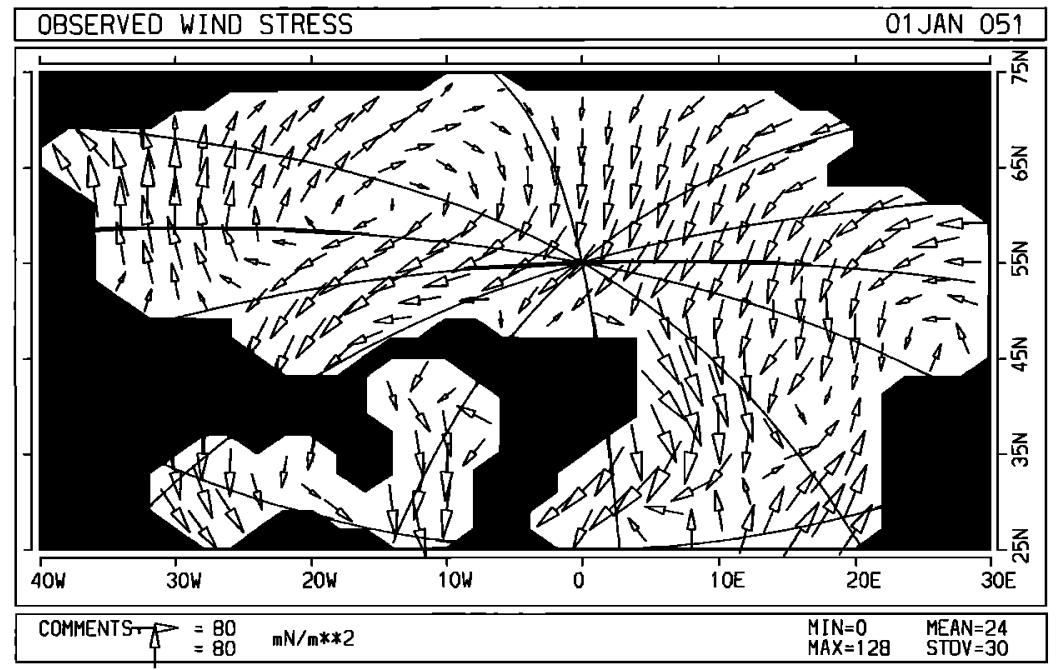

Figure 3c. The wind stress (millinewtons per square meter) for January. A large-scale anticyclonic gyre is evident over the Arctic Basin (the Beaufort Gyre). As well, there is a strong flow directed across the Eurasian Basin toward Fram Strait (the Transpolar Drift Stream). Since each plotted vector corresponds to an actual model grid point, the horizontal resolution used in the model can be inferred from this diagram. 


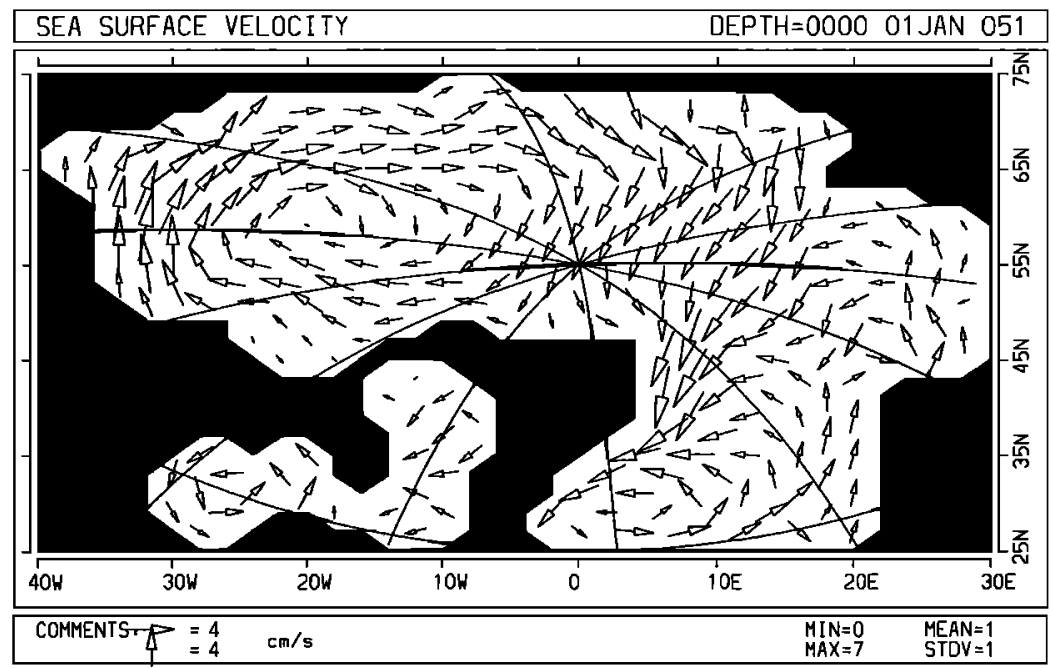

Figure 4a. Mixed-layer velocities (centimeters per second) for January for the control run.

model domain and for each layer, the model solves (5)-(8) to determine the mixed-layer velocity, thickness, temperature, and salinity. Over the vertical extent of the mixed layer, the velocity, temperature, or salinity at a particular grid point represents a single depth-averaged value. The vertical variation of properties within the mixed layer, such as the thin boundary layer between the sea ice and the surface waters, is not simulated. Owing to the excessive number of figures, the simulation results for the seasonal variation are not shown; instead, results from the first day in January are chosen. Any other day of any other month could have been chosen equally well.

The simulated mixed-layer depth (not shown) over the central Arctic Basin has an average value of about $30 \mathrm{~m}$, whereas the depth increases drastically in the GIN Sea and in the Barents Sea, which is consistent with the presence of convective overturning in those regions. There is little seasonal variation of the mixed-layer depth over the central Arctic (i.e., over the Canadian and Eurasian Basins); however, the average mixed-layer depth was noted to be slightly greater at the end of winter than at the end of summer. The deeper mixed layer during winter is consistent with the increased entrainment into the mixed layer during winter. In ice-covered areas this increased entrainment is principally due to salt injection into the mixed layer during ice formation. In ice-free regions the increased mixed-layer depth in winter is due to vigorous wind stirring and also due to convective overturning caused by the increased heat loss from the ocean surface.

The simulated mixed-layer temperature (not shown) equals the freezing point of seawater where ice exists in the domain. There is thus little variation in this quantity throughout the year, as most of the domain is ice covered, and the waters in that part of the domain corresponding to the marginal ice zone do not significantly increase their temperature much above freezing during the ice-free months. The temperature field does show elevated values in the margins of the Arctic Basin where the Siberian rivers flush relatively warm freshwater into the Arctic. This is simply the effect of an elevated freezing point due to a lower salinity. The simulated mixed-layer salinity (not shown) is relaxed in a Newtonian sense to remain near the monthly observed surface values (as an example, see the January distribution shown in Figure $3 b$ ).

Of particular interest is the simulation of the mixed-layer currents (Figure 4a). The patterns for winter (i.e., January (Figure 4a)) and summer (i.e., July (not shown) are similar to one another. They are also relatively consistent with those of observations (Figure 1a) and other models [e.g., Hibler and Bryan, 1987], taking into consideration the coarseness of the model resolution. The TDS is evident and extends from the Siberian coast through to Fram Strait. To the west of the TDS there is an anticyclonic BG which is particularly strong along the Bering Strait. The general circulation in the Eurasian Basin is that of a convergent flow directed toward Fram Strait. In the Barents Sea there is both an inflow of water from the Norwegian Sea and a southward coastal flow of water from the Eurasian Basin. In the GIN Sea the circulation shows a cyclonic gyre, as expected [e.g., Coachman and Aagaard, 1974]. The circulations in Baffin Bay and Hudson Bay are likewise cyclonic. The seasonal variation of currents is minimal except in the Barents Sea. This is not surprising, as the waters in the Barents Sea are shallow and are directly exposed to the seasonally varying wind forcing in that region.

The Oberhuber [1993a] model is a free-surface model and thus predicts the sea surface elevation. Over the Arctic there are no observations of sea surface elevation due to the problem of the ice cover interfering with satellite altimeters. There are, of course, observations of the dynamic height field over the Arctic (Figure 1a) from conductivity-temperature-depth (CTD) measurements. Sea surface elevation and dynamic heights both have units of meters, but they are fundamentally different quantities. However, under the assumption of a level of no motion at depth (i.e., $1200 \mathrm{~m}$ in the case of Figure 1a), the sea surface elevation and the dynamic height are exactly the same quantity at the sea surface (see the appendix). The circulation of the mixed layer of the Arctic has been, to date, inferred from Figure 1a under the assumption of a level of no motion. If the level of no motion is valid, then it is fair to intercompare model-predicted sea surface elevations with observed dynamic heights. It is very unlikely that there does exist a level of no motion; it is more likely that there does exist a surface of no motion which occurs at different depths as one moves horizontally over the ocean. This means that the inferral of surface currents from dynamic heights based on a level of no motion should be done with great caution. For the Arctic there does not exist an adequate set of measurements that describe 


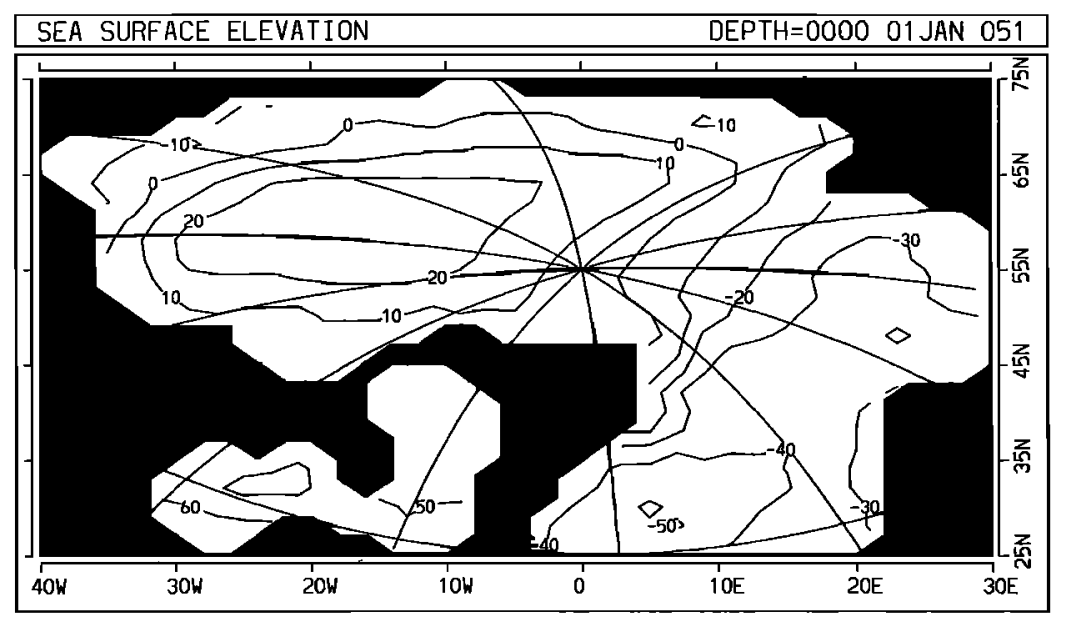

Figure 4b. Sea surface elevation (centimeters) for January for the control run.

the ocean current field at depth. In a study by Holland et al. [1996] the simulation of the very deep currents $(2500 \mathrm{~m})$ produced a maximum speed of about $1 \mathrm{~cm} / \mathrm{s}$. This is much smaller than the surface currents which have a maximum speed of about $4 \mathrm{~cm} / \mathrm{s}$.

For the purpose of intercomparison, the absolute values are not important; rather, it is the relative changes in sea surface elevation or dynamic height that matter. This is because it is the gradient of these quantities that drives flows and not the absolute magnitude. The sea surface elevation (Figure $4 \mathrm{~b}$ ) associated with this circulation is similar in pattern to the dynamic height field presented by Coachman and Aagaard [1974] (Figure 1a). The model simulation (Figure 4b) gives a sea-surface height difference of about $40 \mathrm{~cm}$ between the center of the gyre over the Canadian Basin and the outflow through Fram Strait; the dynamic height observations of Coachman and Aagaard (Figure 1a) give about a 40- to 50-cm difference. The sea-surface elevation in this model shows little seasonal variation.

Leaving aside the question of why, in nature, the mixed layer has the circulation that it does, we can first approach the question of how a model, such as the one employed here, produces the circulation that it does. This is accomplished by carrying out a complete budget analysis of all the individual terms that appear in (5) through (8). For the momentum equation (5) it turns out that the leading terms are the pressure gradient (Figure 5a), the Coriolis force (Figure 5b), and the surface stress (Figure 5c). In fact, over the Arctic the surface stress is smaller than the other two; thus the momentum balance is essentially geostrophic (see Figures $5 \mathrm{a}$ and $5 \mathrm{~b}$ ). The surface stress is comparable to the other terms over the GIN Sea, however.

Though not of primary interest in the present study, the simulated sea ice motion (Figure 6a) is consistent with observations (see Figure 2). The magnitude of the modeled velocities is in good agreement with observations in the vicinity of Fram Strait, being of the order of about $10 \mathrm{~cm} / \mathrm{s}$; however, the modeled velocities appear too large within the central Arctic. The pattern consists of a large BG in the western Arctic and a TDS which flows into a strong southward ice drift along the east Greenland coast. Because of the similarity of this pattern with the wind field (Figure 3c), we conclude that the winds are dominant in driving the sea ice circulation. However, in late summer, when the winds are much lighter, the modeled sea ice

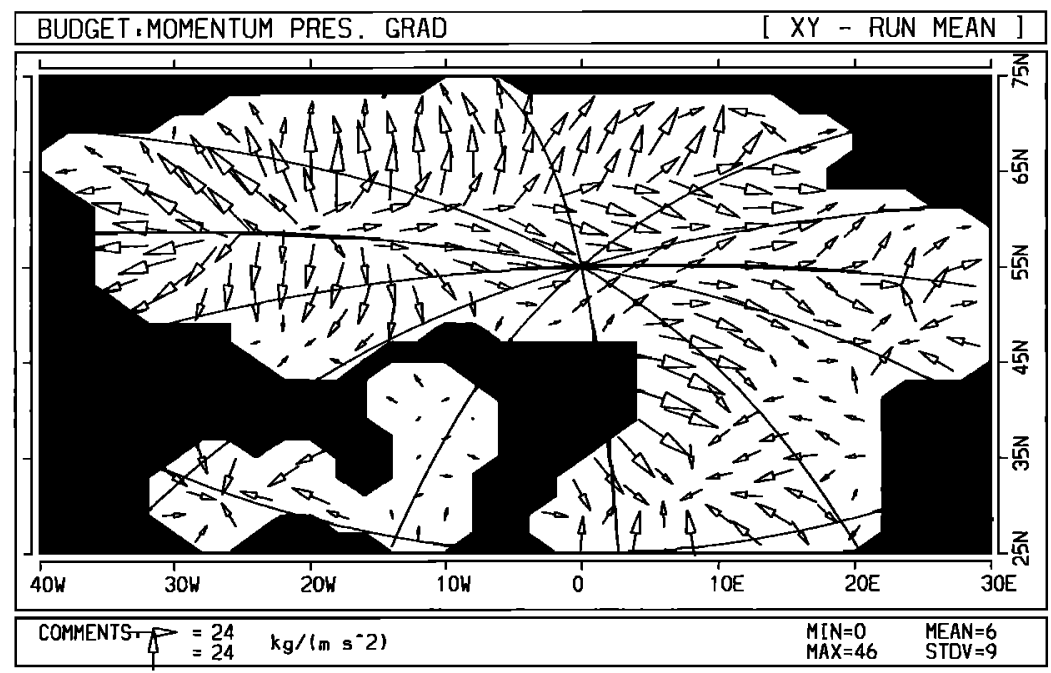

Figure 5a. The pressure gradient contribution for January to the momentum balance for the mixed-layer circulation for the control run. 


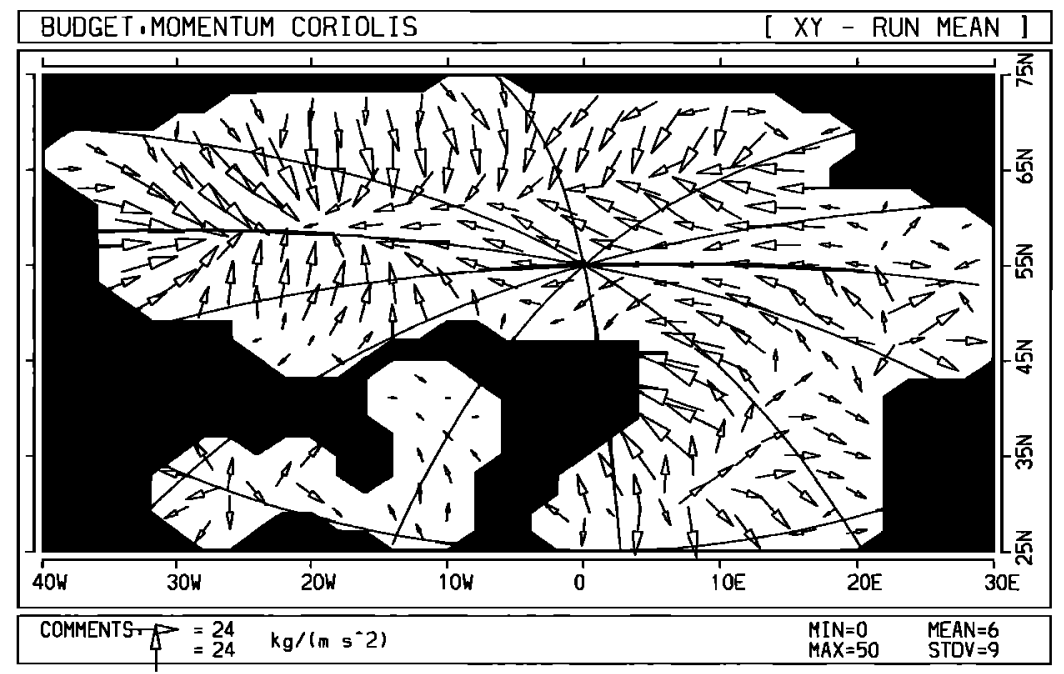

Figure 5b. The Coriolis force contribution for January to the momentum balance for the mixed-layer circulation for the control run.

circulation changes significantly. Observational evidence does exist for the occasional reversal of the sea ice circulation over the Canadian Basin in late summer. Serreze et al. [1989] found that the reversals correspond closely to anomalous (interannual) changes in the atmospheric pressure distribution. However, under climatological forcing there is no reversal of the BG.

The sea ice thickness (Figure 6b) shows a spatial pattern in rough agreement with that deduced by Bourke and Garrett [1987, Figure 5]. However, it is thinner by a factor of 2 along northern Greenland than is actually observed.

As a caveat, it must be added that the sea ice model employed in this study uses a viscous-plastic rheology as in the work by Hibler and Bryan [1987]; however, the wind forcing in the present study uses monthly averaged values and not daily varying ones. To compensate for both these less variable winds and a slightly coarser horizontal resolution, the strength parameter of the ice model was reduced by a factor of $30 \%$ from its nominal value. Such a reduced value is required to prevent the ice from becoming overly rigid and, in places, motionless.
There are many plausible driving mechanisms for the mixedlayer circulation in the Arctic. The cycle of growth and melt of sea ice creates a varying salt flux and freshwater flux which drives buoyancy currents, as does the freshwater flux from river runoff. Another possibility includes a large-scale flow driven by the influxes from the various straits connecting the Arctic to other basins. Also, topography-eddy interactions may generate strong boundary flows (G. Holloway, personal communication, 1993). In an attempt to elucidate the nature of the driving force behind the mixed-layer currents simulated, a series of sensitivity experiments is carried out to illustrate how the modeled circulation responds to various changes in the forcing.

\section{Sensitivity Experiments}

The mixed-layer circulation pattern is investigated with respect to its sensitivity to (1) ice cover, (2) atmospheric winds, (3) sea surface salinity, and (4) initialization without Levitus [1982] data. Though each experiment generally presents a

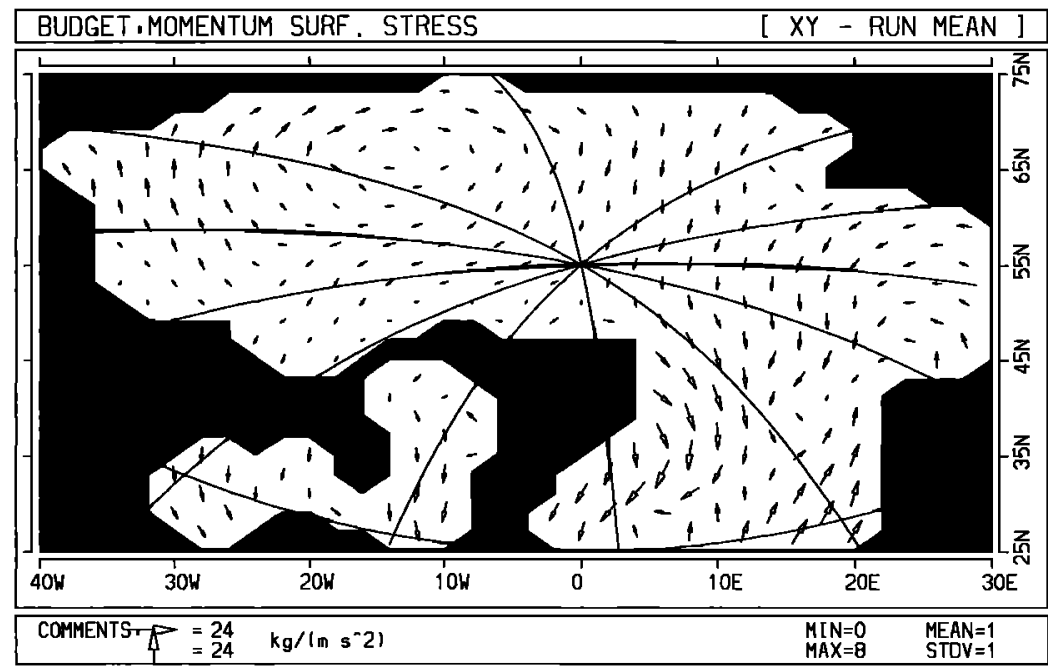

Figure 5c. The surface stress contribution for January to the momentum balance for the mixed-layer circulation for the control run. 


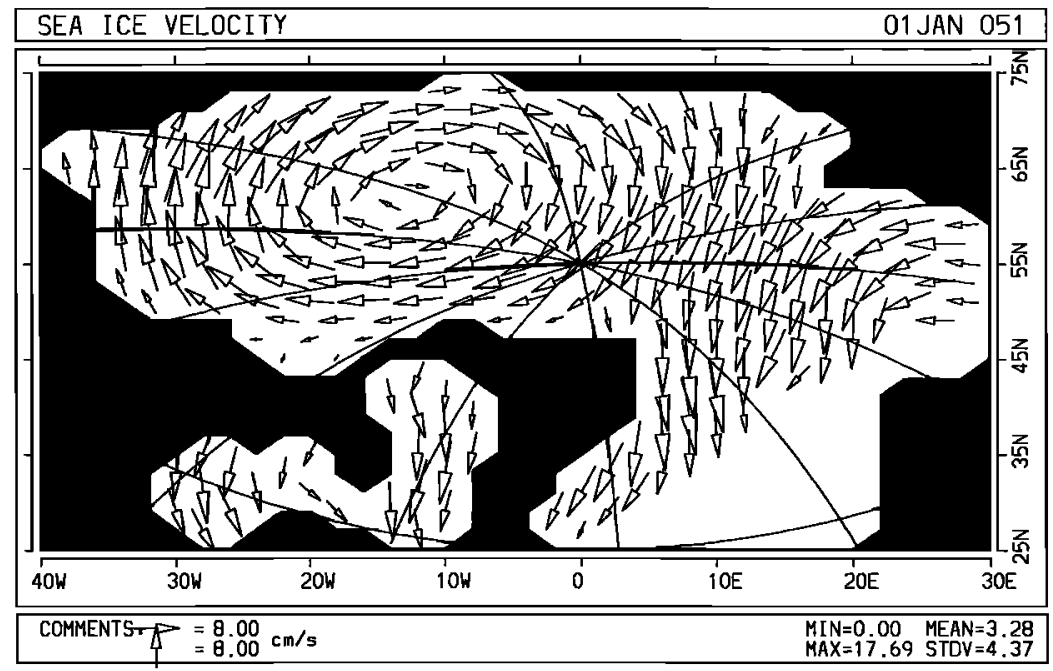

Figure 6a. Sea ice velocity (centimeters per second) for January for the control run.

physically unrealistic situation, it does allow one to clearly identify the contribution that each of the components (1) through (4) makes to the maintenance of the mixed-layer circulation. In particular, we wish to determine whether the mixed-layer circulation is mainly wind-driven or buoyancydriven. A coupled sea ice-mixed layer-deep ocean general circulation model as used here contains numerous parameters and parameterizations. It would be an enormous, yet worthwhile task to investigate the sensitivity of the mixed-layer circulation to changes in these parameters and parameterizations as well. For instance, changes in (1) the drag coefficients between atmosphere and ice and between ice and ocean, (2) the horizontal and vertical diffusion coefficients between layers of the isopycnal model, and (3) the parameterization of salt injection into the ocean during the ice growth process are but a few of the items that may significantly alter the model's simulation of the mixed-layer circulation. Nevertheless, these parameters have been tuned by Oberhuber [1993b] to obtain a reasonable simulation of the North Atlantic, consequently, the same parameter values were employed here. The goal of this sensitivity study presented below is to identify the dominant mechanism driving the mixed-layer circulation in the Arctic rather than to carry out a thorough sensitivity study of the mixed-layer model. Note that in each experiment, only a single change has been made with respect to the control run setup and that each experiment was integrated for 50 years.

\subsection{Ice Cover}

The sea ice cover can be removed by not allowing the climatological air temperatures to fall below $+2{ }^{\circ} \mathrm{C}$. Such a change in air temperature could be envisaged as being due to an Arctic enhanced global warming scenario. As with most sensitivity experiments, this experiment is not physically realistic, as a change in air temperature would also result in a change in wind patterns. Be that as it may, we use the control wind patterns to isolate the impact direct wind forcing has on the circulation. With the sea ice not forming, the mixed layer is directly forced by the atmosphere. The internal stress of the ice is no longer able to extract momentum from the atmosphere. The resulting circulation (Figure $7 \mathrm{a}$ ) is similar to the traditional anticyclonic BG; however, the TDS now flows more toward the Canadian Basin and less toward Fram Strait. The circulation is now more of a reflection of the wind stress (Figure $3 \mathrm{c}$ ) used to force the model. The sea surface elevation

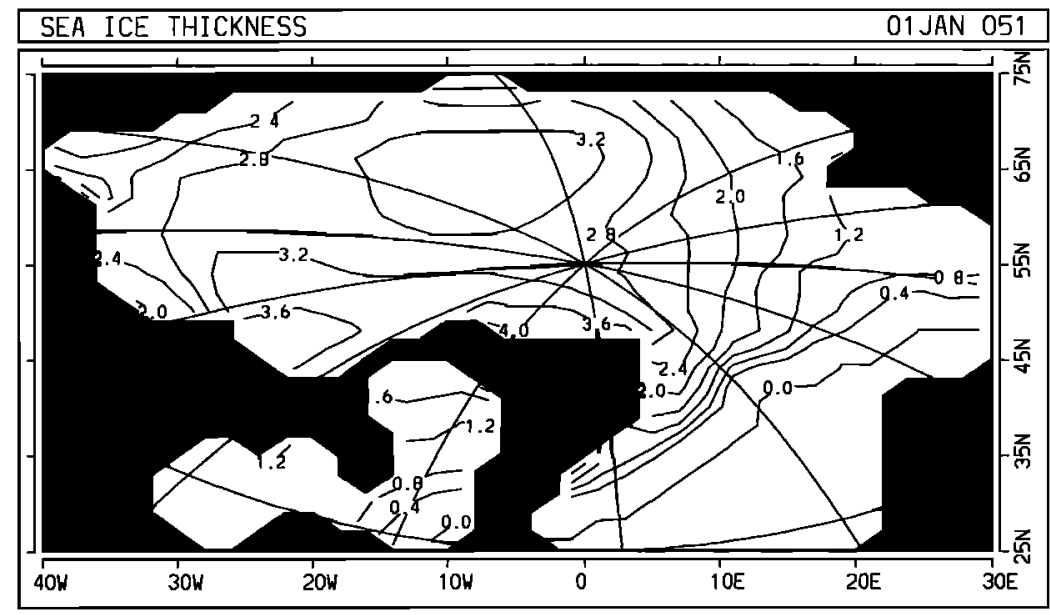

Figure 6b. Sea ice thickness (meters) for January for the control run. 


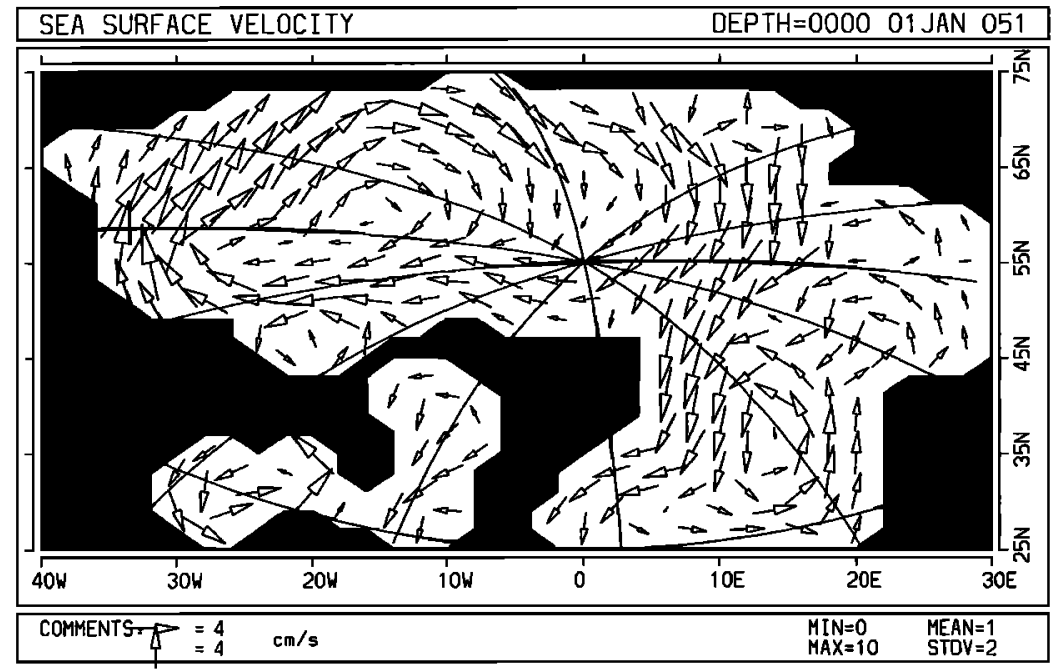

Figure 7a. Mixed-layer velocities (centimeters per second) for January for the experiment with the sea ice cover removed.

(Figure $7 \mathrm{~b}$ ) is similar to the control run (Figure $4 \mathrm{~b}$ ), although the gradients tend to be larger in the Beaufort Sea. The circulation in the ice-free regions, such as the Barents Sea and the GIN Sea, have not changed significantly from the control run (Figure 4a). This is expected, as the shallow water in this region of the domain usually has only a thin ice cover or no ice cover at all. There is little difference in the atmospheric momentum flux or buoyancy flux over the Barents Sea between the control run and this sensitivity run. It can be concluded that it is the direct transfer of momentum from the atmosphere to the ocean that is responsible for the change in circulation pattern.

\subsection{Wind Stress}

In this experiment, only the wind stress is removed. The goal is to observe the circulation pattern in a situation in which the atmosphere does not impart momentum to the mixed layer. The experiment is unrealistic in the sense that the wind is important for producing Ekman divergence and convergence, which in turn makes some contribution to setting up sloping isopycnals that have associated geostrophic currents. The cir- culation (Figure 8a) for this experiment is a weaker (maximum currents are $4 \mathrm{~cm} / \mathrm{s}$ ) than the control run (maximum currents are $7 \mathrm{~cm} / \mathrm{s}$ ), yet the basic pattern remains unchanged over the Arctic. The TDS is now more directed out of the Arctic Basin and toward Fram Strait. The circulation has changed significantly along the Norwegian coast and the Barents Sea coastline. This is not surprising because the ice cover is nonexistent (or thin) in these regions and the wind is expected to play an important role there. The fact that there is little change in the under-ice circulation between this experiment (Figure 8a) and that of the control run (Figure 4a) suggests that the stress between ice and water is not of first-order importance. The sea surface elevation (Figure $8 \mathrm{~b}$ ) shows the same overall features as in the control run (Figure 4b) (although the gradients are weaker in the Beaufort Sea), suggesting that it is not dominated by the wind in this region.

The individual terms of the momentum balance were diagnosed for this experiment (not shown). As expected, the pressure gradient and Coriolis terms are in balance with one an-

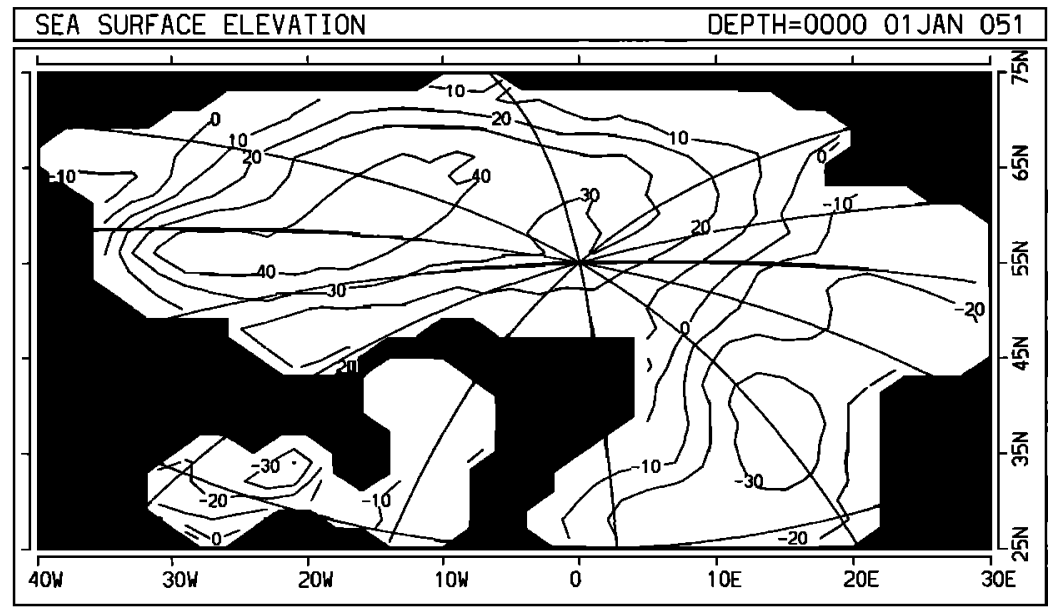

Figure 7b. Sea surface elevation (centimeters) for January for the experiment with the sea ice cover removed. The surface dome over the Canadian Basin is considerably increased in amplitude. 


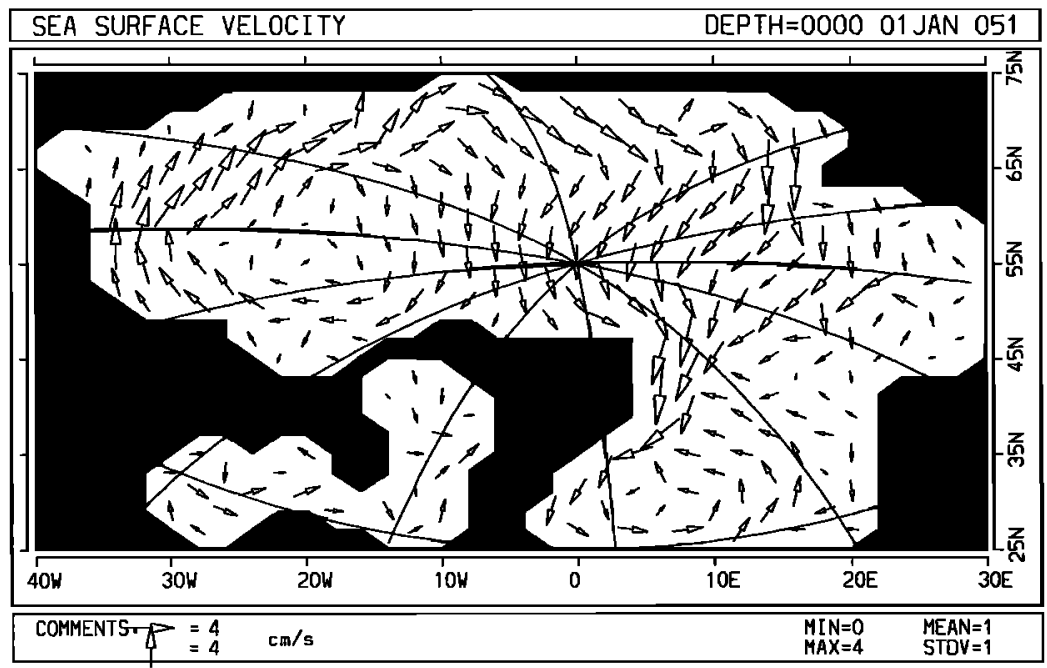

Figure 8a. Mixed-layer velocities (centimeters per second) for January for the experiment with the wind stress removed.

other over the Arctic, while the surface stress is now even less significant than it was in the control run (see Figure $5 \mathrm{c}$ ).

\subsection{Sea Surface Salinity}

To keep the model's cyclostationary state near climatology, the surface salinity in the control run is relaxed to that of climatology (Figure 3b). The model feels the large freshwater impact of the peripheral rivers of the Arctic Basin through this imposed salinity field. Likewise, the model feels the relatively saline tongues from the Bering and Fram Strait regions (see Figure 3b). In this experiment the annual climatological surface salinity field is replaced by a constant field of 32 practical salinity units (psu) everywhere. This value was chosen as an intermediate value between the low salinities near river mouths and the high salinities found in the GIN Sea. The result is that the near-surface isopycnal surfaces across the Arctic Basin become much more horizontal. In the control run the presence of large gradients of surface salinity produces strong slopes in the isopycnic surfaces, even in the mixed layer. These sloping isopycnals give rise to baroclinic currents which con- tribute to the total circulation. Note that in this experiment the wind is still allowed to exert a force on the ice.

With uniform surface salinity the circulation (Figure 9a) is now drastically altered in the Arctic but not in the GIN Sea. The flow pattern in the Arctic is now everywhere toward the central Arctic, where the water then sinks. The sea surface elevation (Figure $9 \mathrm{~b}$ ) has changed dramatically; it has flattened out over the Arctic. Without a realistic sea surface salinity field, either relaxed to observations as in the control run or prognostically computed (as will be done in the future), there is no possibility of getting a realistic mixed-layer circulation.

Further insight into the importance of salinity can be gained by looking at the momentum budget for this experiment. In contrast to the control run, the pressure gradient (Figure 10a), the Coriolis force (Figure 10b), and the surface stress (Figure 10c) are all comparable over the Arctic. Recall that the control run (Figures 5a-5c) held a geostrophic balance over the Arctic. The pattern of Figure 9a is now comprehensible, the surface motion of the ice (Figure 10c) is forcing the mixed-layer mo-

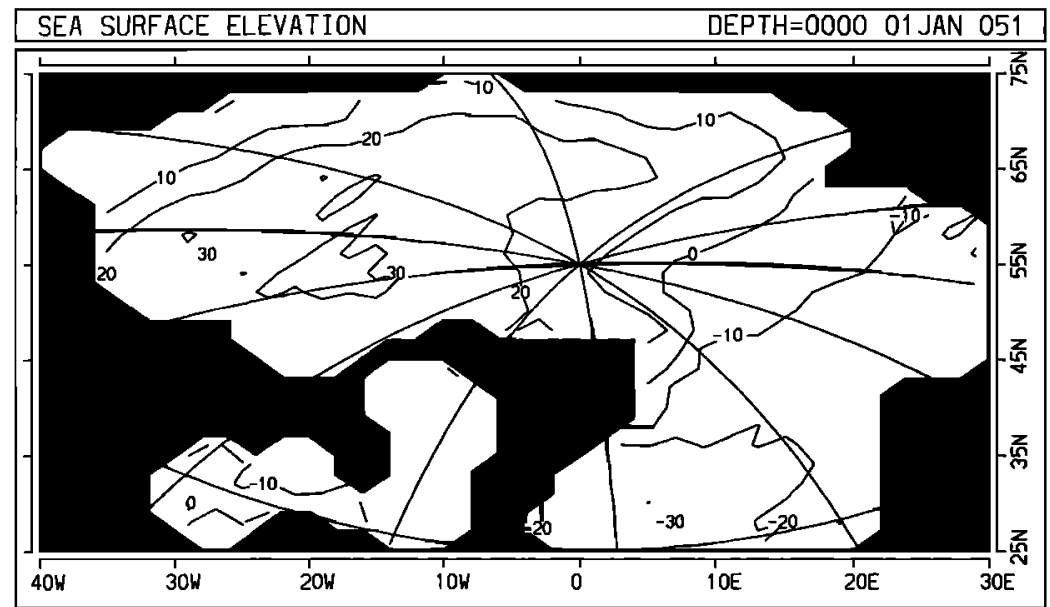

Figure 8b. Sea surface elevation (centimeters) for January for the experiment with the wind stress removed. The surface dome over the Canadian Basin is considerably decreased in amplitude compared with the control run. 


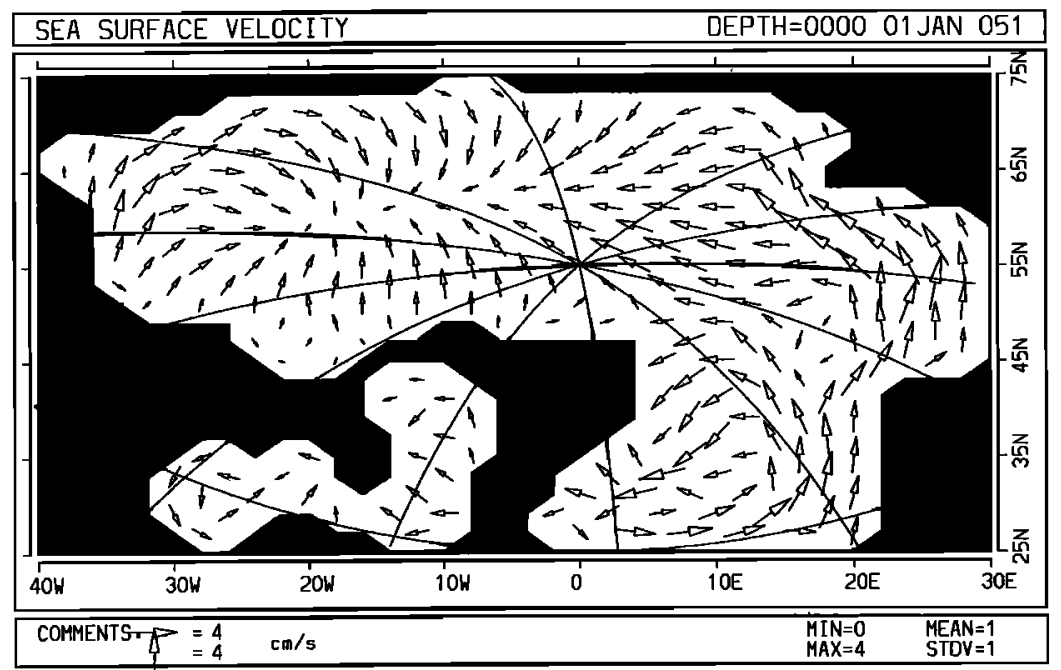

Figure 9a. Mixed-layer velocities (centimeters per second) for January for the experiment with modified sea surface salinity. The wind forcing in this experiment is the same as in the control run.

tion. The mixed layer responds with an Ekman flow to the right of the surface stress. It thus flows toward the center of the Arctic.

We conclude that the observed surface salinity spatial pattern, which is caused by ice melt and growth, river runoff, precipitation and evaporation, saline tongues from Bering and Fram Straits, and Ekman convergence of the mixed layer, is the key factor controlling the circulation.

\subsection{Levitus Data}

Ordinarily, at the beginning of the integration the model's isopycnal surfaces are determined from the temperature and salinity data of Levitus [1982]. This data set is spotty in the Arctic Ocean, where there are an inadequate number of observations to specify the temperature and salinity fields in a satisfactory manner. Thus, as an experiment, the model was spun up using level isopycnals. However, as a surface boundary condition, the salinity is still relaxed. The idea is to test how the deep circulation affects the surface circulation. After the first decade of integration the surface circulation pattern (not shown) is more intense (maximum currents are $12 \mathrm{~cm} / \mathrm{s}$ ) than in the control run (maximum currents are $7 \mathrm{~cm} / \mathrm{s}$ ). In addition, the sea surface elevation indicates an enhanced height difference of about $60 \mathrm{~cm}$ between the central Arctic and Fram Strait (compared to $40 \mathrm{~cm}$ for the control run). However, by the end of the fifth decade of integration this experiment produces an identical circulation to that of the control run.

In the control run the deep circulation in the Arctic has a cyclonic sense and thus opposes the circulation in the mixed layer. The deep waters of the Arctic feel the sea surface elevation and apparently try to compensate for this pressure gradient by creating a pressure gradient at depth which opposes the surface one. In this model the pressure gradient at depth actually overcompensates for the surface pressure gradient and causes the waters to flow opposite to the surface sense. This variation in pressure gradient at depth comes from horizontal variations in salinity at depth.

In this sensitivity experiment, initializing the model with level isopycnals means that the deep water properties do not have adequate time after the first decade to create a deep salinity structure which is capable of opposing the surface circulation; however, at the end of the fifth decade there is

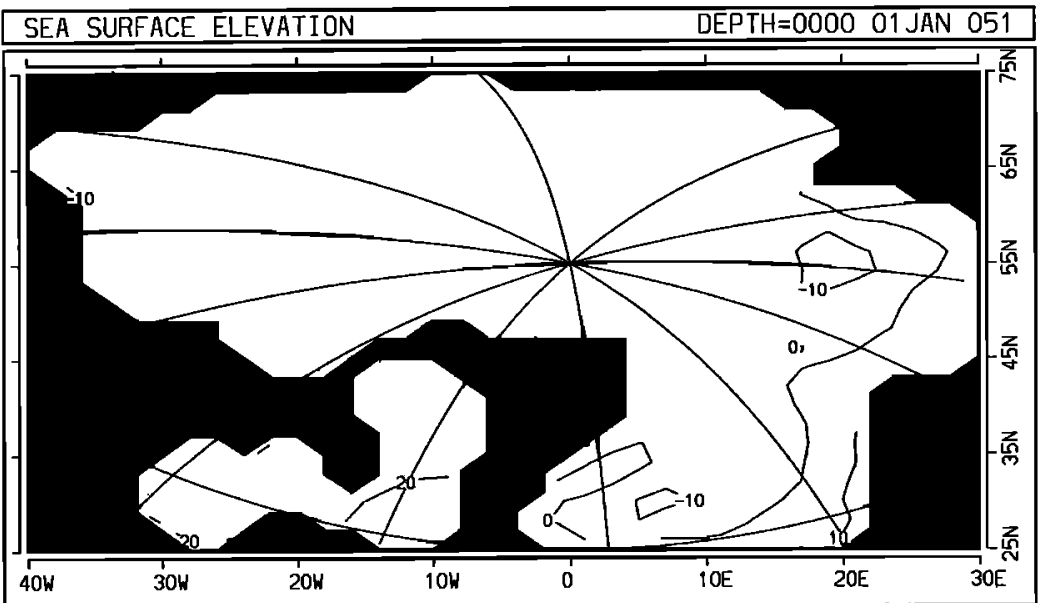

Figure 9b. Sea surface elevation (centimeters) for January for the experiment with modified sea surface salinity. The surface dome over the Canadian Basin has disappeared. 


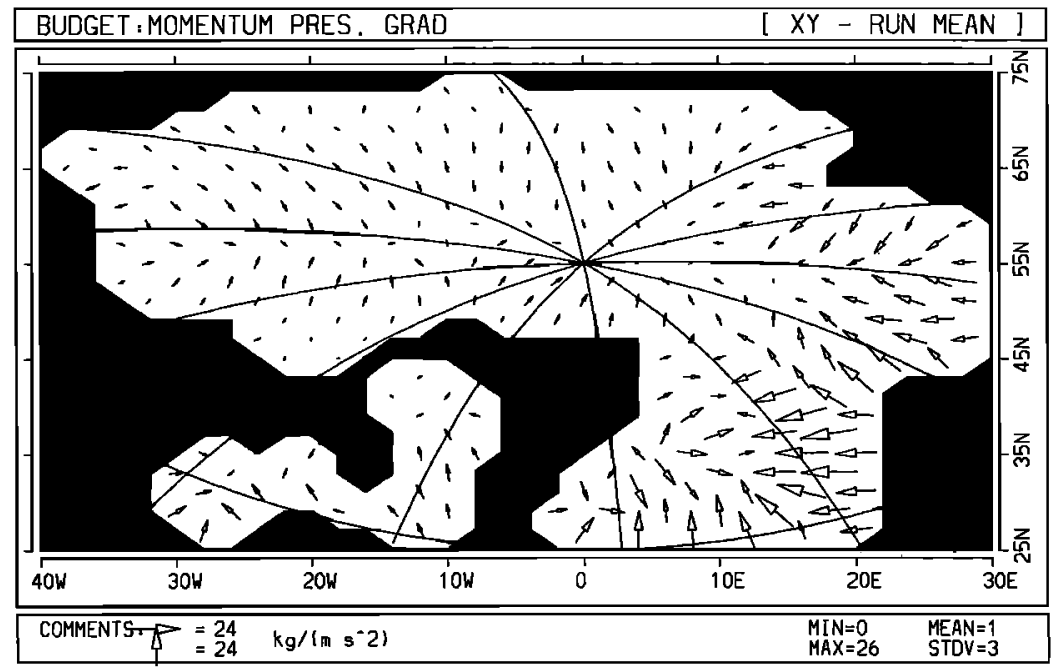

Figure 10a. The pressure gradient contribution for January to the momentum balance for the mixed-layer circulation for the experiment with modified sea surface salinity.

baroclinic compensation occurring at depth and the surface circulation is the same as the control run (Figure 4a). The conclusion is that the deep circulation matters to the surface circulation in a baroclinic, salt-driven ocean. Adequate time must be given for the deep circulation to reach its basic equilibrium state. In this instance, five decades seem adequate.

\section{Conclusions}

The application of a recently developed coupled sea icemixed layer-isopycnal ocean general circulation model [Oberhuber, 1993a] to the Arctic Ocean has produced some new results for the importance of surface bouyancy fluxes to the mixed-layer circulation. The four sensitivity experiments presented here complement two earlier sensitivity experiments carried out by Ranelli and Hibler [1991]. The conclusion of both studies is that the exchange of freshwater at the surface of the Arctic Ocean is crucial to the circulation.

In this study the sea ice simulation was satisfactory in that it showed a reasonably well developed anticyclonic BG and TDS extending from the Siberian coast to Fram Strait. This occurred despite an ocean circulation which did not mimic the sea ice flow. This indicates the dominance of the winds in controlling the ice drift pattern over most of the Arctic.

The four sensitivity experiments proved useful in elucidating the contribution made by various processes in driving the mixed-layer circulation. (1) In the absence of a sea ice cover the circulation is more wind-driven than in the control run. (2) In the absence of wind stress the circulation differs from the control only in regions of thin or nonexistent ice cover. (3) In the absence of a realistic sea surface salinity field the circulation is completely unrealistic. (4) In the absence of initialization with Levitus [1982] data the circulation initially lacks the baroclinic compensation that the deep Arctic provides to the mixed layer; however, after five decades it reaches the same equilibrium as the control run.

A limitation of the present study is the discretization of the

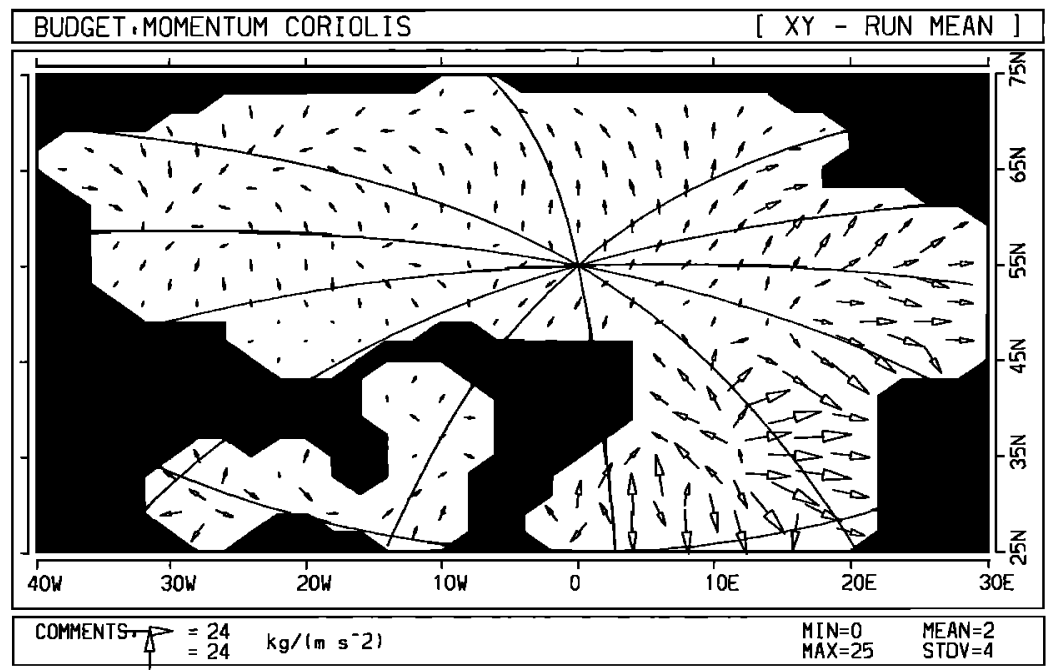

Figure 10b. The Coriolis force contribution for January to the momentum balance for the mixed-layer circulation for the experiment with modified sea surface salinity. 


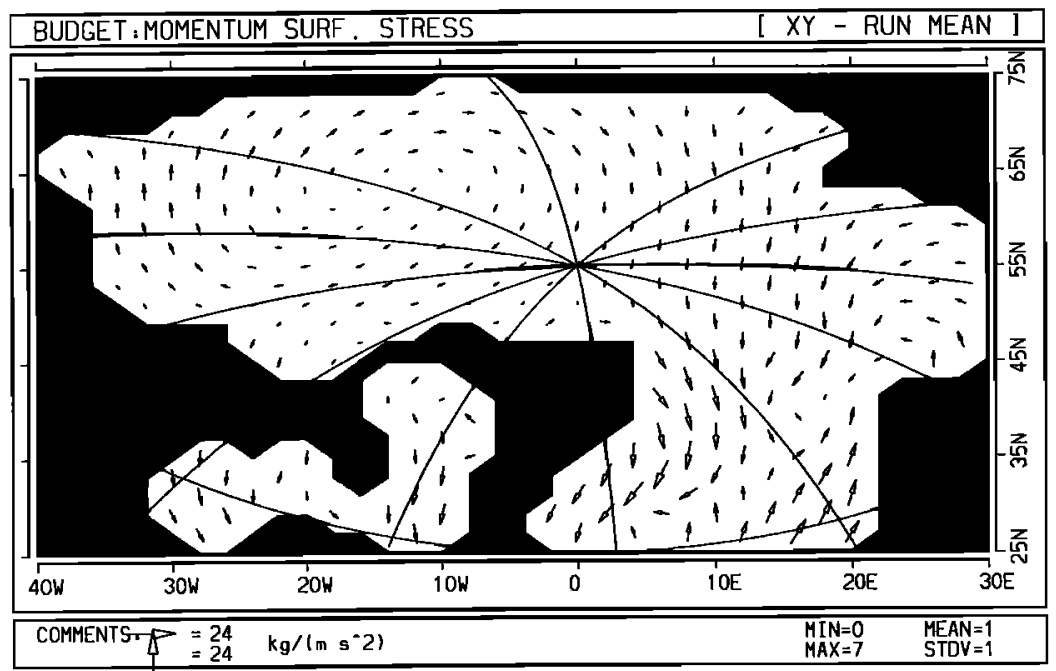

Figure 10c. The surface stress contribution for January to the momentum balance for the mixed-layer circulation for the experiment with modified sea surface salinity.

vertical into only five layers and the use of a horizontal resolution of only $2^{\circ}$. It is possible that the control run is outside the realm of response that is characteristic of the real ocean. Thus the results obtained from removing individual components of the system may be incorrect. The resolution used is imposed upon us by the computing resources presently available. The same comments apply to global atmosphere-ocean climate experiments which are presently run at an even coarser resolution than used here. Further studies are in progress involving an increased number of vertical layers and a higher horizontal resolution as well as a larger domain that will include exchanges with the North Atlantic and North Pacific Oceans.

The Arctic is a unique ocean with unique dynamics. It has a mixed-layer circulation that is strongly influenced, and possibly critically controlled, by the surface freshwater flux. Future research on this point with a variety of ocean models could elucidate this. Compared with other oceans, the presence of an ice cover enhances this haline component (via ice growth and melt) and simultaneously diminishes the wind-driven component (via ice internal stress).

\section{Appendix}

Under the assumption of a level of no motion at depth we show that the fields of dynamic height and sea surface elevation give the same spatial information, i.e., the relative height of the sea surface to a reference geoid. It is argued that if there exists a level of no motion at depth, then the intercomparison of sea surface elevation and dynamic height is valid. If such a level of no motion does not exist, then the following derivation is erroneous. It would also follow, in that case, that all previous studies which have inferred the Arctic mixed-layer circulation from the observed dynamic height field would be incorrect.

The basis of the intercomparison is that we assume that the mixed-layer currents derived from the sea surface elevation field and the dynamic height field are the same. First, we assume that the sea surface elevation gives the mixed-layer circulation simply by geostrophic balance between the pressure gradient, arising from the sea surface slope, and the Coriolis force. Second, we know that dynamic heights give us the relative flow between the mixed layer and the deep ocean. By demanding the deep ocean to be at rest (a level of no motion), as is frequently done, then we get the absolute value of the mixed-layer currents.

Another way to look at this is to say that the sea surface elevation field produces a horizontal pressure gradient field which is felt at the surface of the ocean and all the way to the bottom. Without baroclinic effects there would be uniform flow at all depths. The claim often made by oceanographers, that there exists a level of no motion in the deep ocean, is a statement that as one passes down from the surface to the deep ocean, then horizontal variations in density (a baroclinic effect) operate in such a way as to exactly cancel the horizontal variations in pressure imposed by the sea surface elevation (a barotropic effect).

The following derivation shows the equivalence of the dynamic height and the sea surface elevation. First, consider the sea-surface elevation field $\eta$. The pressure generated by the sea surface elevation is $p=\rho g \eta$. Using the geostrophic relation [Gill, 1982, p. 214]

$$
f v=\frac{1}{\rho} \frac{\partial p}{\partial x}
$$

it follows that the required change in sea surface elevation $\Delta \eta$ to produce a flow of velocity $v$, averaged over a width of ocean $\Delta x$, is

$$
\Delta \eta=\frac{f v \Delta x}{g}
$$

Second, consider the dynamic height field $Z$. The geostrophic relation expressed in terms of dynamic height is [Gill, 1982, p. 214]

$$
f v=g \frac{\partial Z}{\partial x}
$$

It follows that the required change in dynamic height $\Delta Z$ to produce a velocity $v$ at the surface (with a level of no motion in the deep ocean), averaged over a width of ocean $\Delta x$, is

$$
\Delta Z=\frac{f v \Delta x}{g}
$$


Comparing (A2) and (A4), the conclusion is that the quantities $\Delta \eta$ and $\Delta Z$ are the same.

Acknowledgments. Computing support for this project was provided by a Cray supercomputing grant from the Arctic Region Supercomputing Center (ARSC) at the University of Alaska, Fairbanks. D. $M$. H. is grateful for graduate student support from the Newfoundland Government Career Development Awards Programme and a scholarship from the Canadian Atmospheric Environment Service (AES). L. A. M. is grateful for research support from the AES, the Canadian Natural Sciences and Engineering Research Council (NSERC), and the United States Office of Naval Research. J. M. O. is grateful for support from the German Bundesminister fur Forschung und Technologie. Constructive criticism by W. D. Hibler III improved the manuscript.

\section{References}

Aagaard, K., The Beaufort Undercurrent, in The Alaskan Beaufort Sea, Ecosystems and Environments, edited by P. W. Barnes, D. M. Schell, and E. Reimnitz, pp. 41-71, Academic, San Diego, Calif., 1984.

Aagaard, K., A synthesis of the Arctic Ocean circulation, Rapp. $P$. V. Reun. Cons. Int. Explor. Mer., 188, 11-22, 1989.

Björk, G., A one-dimensional time-dependent model for the vertical stratification of the upper Arctic Ocean, J. Phys. Oceanogr., 19, 52-67, 1989.

Bourke, R. H., and R. P. Garrett, Sea ice thickness distribution in the Arctic Ocean, Cold Reg. Sci. Technol., 13, 2107-2117, 1987.

Campbell, W. J., The wind-driven circulation of ice and water in a polar ocean, J. Geophys. Res., 70, 3279-3301, 1965.

Coachman, L. K., and K. Aagaard, Physical oceanography of Arctic and Subarctic Seas, in Marine Geology and Oceanography of the Arctic Seas, edited by E. Herman, pp. 1-72, Springer-Verlag, New York, 1974.

Coachman, L. K., and C. A. Barnes, The contribution of Bering Sea water to the Arctic Ocean, Arctic, 14, 147-160, 1961.

Colony, R. L., I. Rigor, and K. Runciman-Moore, A summary of observed ice motion and analyzed atmospheric pressure in the Arctic Basin, 1979-1990, Tech. Memo. APL-UW TM13-91, 106 pp., Appl. Phys. Lab., Univ. of Wash., Seattle, 1991.

Cox, M. D., A primitive equation, three-dimensional model of the ocean, GFDL Ocean Group Tech. Rep. 1, 250 pp., Geophys. Fluid Dyn. Lab., Princeton Univ., Princeton, N. J., 1984.

Galt, J. A., A numerical investigation of Arctic Ocean dynamics, $J$. Phys. Oceanogr., 3, 379-396, 1973.

Gill, A. E., Atmosphere-Ocean Dynamics, Int. Geophys. Ser., vol. 30, 662 pp., Academic, San Diego, Calif., 1982.

Hibler, W. D., III, A dynamic thermodynamic sea ice model, J. Phys. Oceanogr., 9, 815-846, 1979.

Hibler, W. D., III, and K. Bryan, A diagnostic ice-ocean model, J. Phys. Oceanogr., 17, 987-1015, 1987.

Holland, D. M., L. A. Mysak, D. K. Manak, and J. M. Oberhuber, Sensitivity study of a dynamic-thermodynamic sea-ice model, J. Geophys. Res., 98, 2561-2586, 1993.
Holland, D. M., L. A. Mysak, and J. M. Oberhuber, The simulation of the Atlantic-layer circulation in the Arctic Ocean, Tellus, Ser. A, in press, 1996.

Levitus, S., Climatological atlas of the world ocean, NOAA Prof. Pap. 13, 173 pp., U.S. Govt. Print. Off., Washington, D. C., 1982.

National Geophysical Data Center, ETOPO5, 5-minute gridded world elevations and bathymetry-A digital data base, U.S. Dept. of Commer., Boulder, Colo., 1987.

Newton, J. L., The Canada basin: mean circulation and intermediatescale flow features. Ph.D thesis, 158 pp., Univ. of Wash., Seattle, 1973.

Oberhuber, J. M., An atlas based on the COADS data set: The budgets of heat, buoyancy, and turbulent kinetic energy at the surface of the global ocean, Rep. 15, 199 pp., Max-Planck-Inst. for Meteorol. Hamburg, Germany, 1988.

Oberhuber, J. M., Simulation of the Atlantic circulation with a coupled sea ice-mixed layer-isopycnal general circulation model, I, Model description, J. Phys. Oceanogr., 23, 808-829, 1993 a.

Oberhuber, J. M., Simulation of the Atlantic circulation with a coupled sea ice-mixed layer-isopycnal general circulation model, II, Model experiment, J. Phys. Oceanogr., 23, 830-845, 1993b.

Parkinson, C. L., C. J. Josefino, H. J. Zwally, D. J. Cavalieri, P. Gloersen, and W. J. Campbell, Arctic sea ice 1973-1976: Satellite passive microwave observations, NASA Spec. Publ. SP-489, 1987.

Ranelli, P. H., and W. D. Hibler III, Seasonal Arctic sea-ice simulations with a prognostic ice-ocean model, Ann. Glaciol., 15, 155-162, 1991.

Semtner, A. J., Jr., Numerical simulation of the Arctic Ocean circulation, J. Phys. Oceanogr., 6, 409-425, 1976.

Semtner, A. J., Jr., A numerical study of sea ice and ocean circulation in the Arctic, J. Phys. Oceanogr., 17, 1077-1099, 1987.

Serreze, M. C., R. G. Barry, and A. S. McLaren, Seasonal variations in sea-ice motion and effects on sea-ice concentrations in the Canada Basin, J. Geophys. Res., 94, 10,955-10,970, 1989.

Smith, W. O., Polar Oceanography, Part A, Physical Science, pp. 171222, Academic, San Diego, Calif., 1990.

Wright, P., An atlas based on the COADS data set: Fields of mean wind, cloudiness, and humidity at the surface of the global ocean, Rep. 14, 70 pp., Max-Planck-Inst. for Meteorol., Hamburg, Germany, 1988.

D. M. Holland, Lamont-Doherty Earth Observatory, Columbia University, P. O. Box 1000, Route 9W, Palisades, NY 10964-8000. (e-mail: holland@rosie.ldeo.columbia.edu)

L. A. Mysak, Department of Atmospheric and Oceanic Sciences and Centre for Climate and Global Change Research, McGill University, 805 Sherbrooke Street West, Montreal, Quebec, Canada H3A 2K6.

J. M. Oberhuber, German Climate Computer Center, Bundesstrasse 55, 20146 Hamburg, Germany.

(Received August 5, 1994; revised April 26, 1995; accepted May 5, 1995.) 